\title{
Carbon Nanofiber Synthesis within 3-Dimensional Sintered Nickel Microfibrous Matrices: Optimization of Synthesis Conditions
}

\author{
Amogh N. Karwa, Virginia A. Davis, and Bruce J. Tatarchuk \\ Department of Chemical Engineering, Auburn University, Auburn, AL 36849, USA \\ Correspondence should be addressed to Bruce J. Tatarchuk, tatarbj@auburn.edu \\ Received 9 January 2012; Revised 3 May 2012; Accepted 7 May 2012 \\ Academic Editor: Bobby G. Sumpter
}

Copyright ( 2012 Amogh N. Karwa et al. This is an open access article distributed under the Creative Commons Attribution License, which permits unrestricted use, distribution, and reproduction in any medium, provided the original work is properly cited.

This study focuses on the process of optimization for carbon nanofiber synthesis at the exterior and the interior of 3-dimensional sintered nickel microfibrous networks. Synthesis of carbon nanofibers (CNF) by catalytic decomposition of acetylene (ethyne) was conducted at atmospheric pressure and short reaction times (10 min). Two factors evaluated during the study were (a) CNF quality (observed by SEM and Raman spectroscopy) and (b) rate of reaction (gravimetrically measured carbon yield). Independent optimization variables included redox faceting pretreatment of nickel, synthesis temperature, and gas composition. Faceting resulted in an 8-fold increase in the carbon yield compared to an untreated substrate. Synthesis with varying levels of hydrogen maximized the carbon yield $\left(9.31 \mathrm{mg} \mathrm{C} / \mathrm{cm}^{2}\right.$ catalyst). The quality of $\mathrm{CNF}$ was enhanced via a reduction in amorphous carbon that resulted from the addition of $20 \%$ ammonia. Optimized growth conditions that led to high rates of CNF deposition preferentially deposited this carbon at the exterior layer of the nickel microfibrous networks $\left(570^{\circ} \mathrm{C}, 78 \% \mathrm{H}_{2}, 20 \% \mathrm{NH}_{3}, 2 \% \mathrm{C}_{2} \mathrm{H}_{2}\right.$, faceted Ni.). CNF growth within the 3-dimensional nickel networks was accomplished at the conditions selected to lower the gravimetric reaction rate $\left(470^{\circ} \mathrm{C}, 10 \% \mathrm{H}_{2}, 88 \% \mathrm{~N}_{2}, 2 \% \mathrm{C}_{2} \mathrm{H}_{2}\right.$, nonfaceted $\mathrm{Ni}$ ).

\section{Introduction}

Dusting corrosion of metal components in the hydrocarbon processing industry (due to the formation of solid carbon at high temperatures) provided the early impetus for carbon deposition studies in the 1960s. In the 1970s, fibrous carbon structures were extensively investigated under the generic category of "carbon filaments" using high-resolution electron microscopes [1-6]. Even though carbon nanotubes of $2 \mathrm{~nm}$ diameter were observed in 1976 [7], these observations did not attract significant attention at the time. The high level of interest in carbon nanofibers (CNF) and carbon nanotubes (CNT) in the 1990s resulted from the discovery of buckyballs $\left(\mathrm{C}_{60}\right)$ in 1985 [8] and a better appreciation of nanotubes in 1991 [9]. Since that time, extensive research is ongoing involving the synthesis and manipulation of these nanomaterials for a variety of applications including electron field emission [10-12], molecular electronics [13-19] and nanocomposites [20-22].
Nickel, cobalt, and iron have been used as active catalysts for CNF/CNT synthesis since the 1970s. It is often reported that the catalyst size determines the diameter of the CNT/CNF $[23,24]$. In order to control the dimensions of the catalyst, CNT has been synthesized on nanoparticles dispersed on a flat support $[24,25]$ or using organometallic precursors in the gas phase at high pressures [26-29]. However, CNF/CNT synthesis on bulk metal substrates is challenging because the exact dimensions of the catalyst cannot be controlled, and as a result high levels of amorphous carbon may be formed. Several investigators have reported synthesis of CNF/CNT on bulk stainless steel substrates [30-35]; however, there are relatively few reports of CNF synthesis on bulk nickel metal substrates such as foams [3638], screens/grids [39], and foils [40-43]. Pretreatment of the bulk metal has been studied for its effects on CNF/CNT growth. Acid etching has been reported to be advantageous on stainless steel substrates due to an increase in surface roughness [44, 45]. Kukovitsky et al. synthesized CNF using 


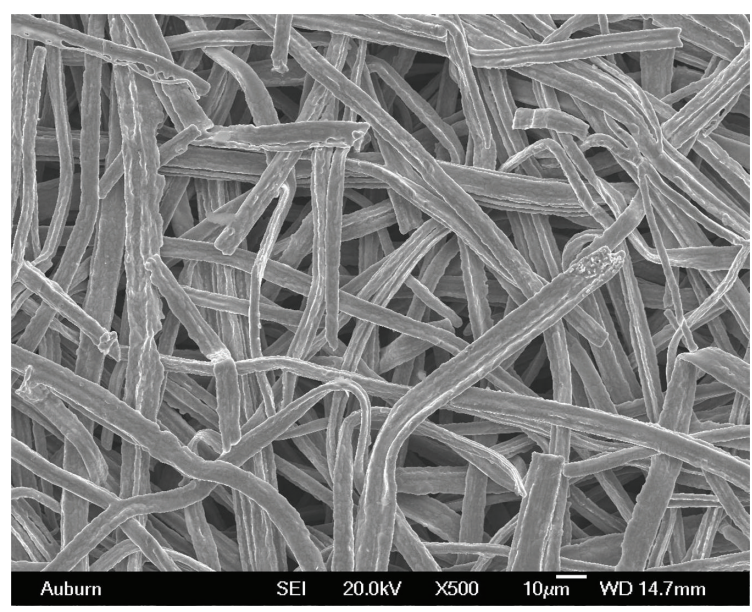

FIGURE 1: SEM image of nickel sintered metal microfibrous (SMM) matrix made with $4 \mu \mathrm{m}$ (dia.) nickel microfibers.

polyethylene on nickel foils after mechanical and chemical polishing pretreatments [42].

This study was undertaken to optimize the CNF synthesis conditions for 3-dimensional high surface area nickel sintered metal microfibrous (SMM) substrates/matrices. Figure 1 shows a SMM matrix made with $4 \mu \mathrm{m}$ (dia.) nickel microfibers. The unique challenge for $\mathrm{CNF}$ synthesis on SMM matrices stems from their relatively high surface area. The process of optimization shown in this study aimed at finding whether CNF (with low amorphous carbon) can be synthesized only on the surface of the SMM matrix, as shown in Figure 2(a), or within the entire 3-dimensional SMM matrix as shown in Figure 2(b). These two different structures were desired keeping in mind the potential engineering applications. Surface deposition of CNF on SMM can create a membrane-like structure with very small pores, whereas 3-dimensional deposition within the SMM matrix can provide benefits for other process applications such as liquid or air filtration [46]. Variations in the growth layer morphology of CNF were thought to be possible by varying the rate of reaction for CNF synthesis. For a SMM matrix acting as a catalyst bed, a high rate of reaction should result in CNF being formed only on the outer layers of the matrix, whereas a lower rate of reaction could lead to CNF synthesis within the interior of the SMM matrix. Parameters such as catalyst pretreatment, synthesis temperature, and gas composition were optimized to achieve these two growth morphologies.

\section{Experimental}

2.1. Materials. Ribbon-shaped nickel microfibers (alloy Ni200) of metal purity $>99 \%$ with nominal diameter of $4 \mu \mathrm{m}$ and $8 \mu \mathrm{m}$ and lengths of $3 \mathrm{~mm}$ and $6 \mathrm{~mm}$, respectively, were obtained from Intramicron Inc. (Auburn, AL). Coldrolled polycrystalline nickel foil of $99.5 \%$ purity (metal basis) and thickness of $0.1 \mathrm{~mm}$ was obtained from Alfa Aesar (stock number 44821). High purity nitrogen (99.999\%),

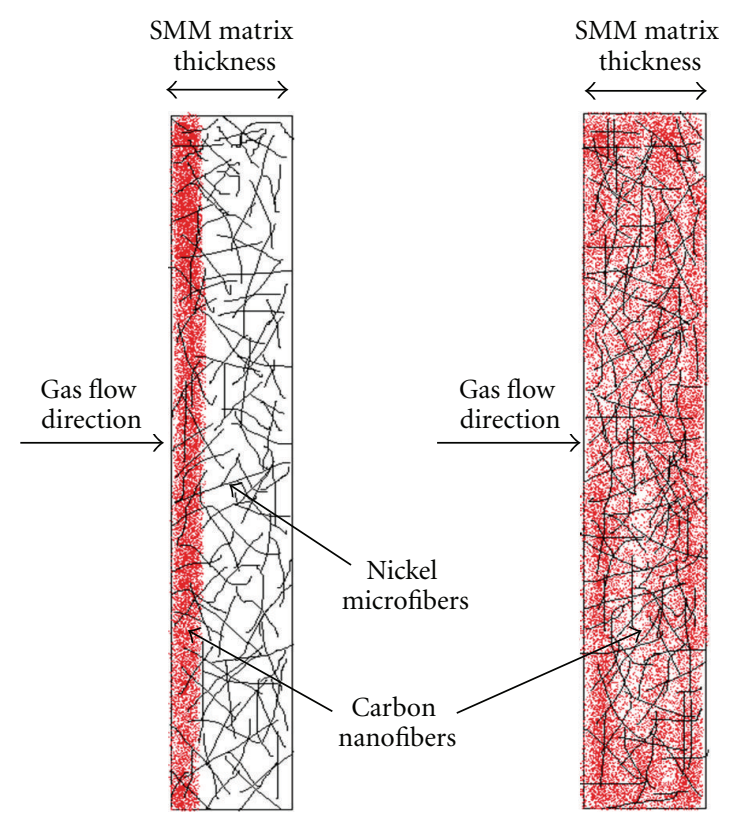

(a)

(b)

FIGURE 2: Side-view schematic diagram of sintered metal microfibrous (SMM) matrix with (a) surface synthesis of CNF and (b) 3dimensional synthesis of CNF.

hydrogen $(99.999 \%)$, acetylene (99.6\%), anhydrous ammonia (99.999\%), and breathing quality dry air $(<67 \mathrm{ppm}$ moisture) supplied from Airgas Inc. were used.

2.2. Method. Nickel sintered metal microfibrous (SMM) matrices were prepared by dispersing the nickel microfibers in water using a laboratory mixer and/or blender. The viscosity of water was increased by the addition of $0.75 \%$ $(\mathrm{w} / \mathrm{w})$ hydroxyethyl cellulose. The increased viscosity of water and the optimized dispersion methodology prevented excessive reduction in the aspect ratio of nickel microfibers during dispersion. The nickel microfiber dispersions were used to make preforms of the SMM matrices by wet-lay formation using a $16 \mathrm{~cm}$ (dia.) TAPPI hand-sheet former. These preforms were sintered for $40 \mathrm{~min}$ at a temperature of $950^{\circ} \mathrm{C}$ in a reducing environment of $10 \%$ hydrogen in nitrogen to form SMM matrices. Samples of the required dimensions were punched out using a steel punch and were compressed to reduce the voidage of SMM matrices. The thickness of the samples used in this study was $\sim 0.36 \mathrm{~mm}$ with voidage of $\sim 76 \%$. The SMM matrices have relatively large surface area because of the microfibers used to make SMM matrices. These SMM matrices were used as the catalysts for CNF synthesis.

The thermal chemical vapor deposition (CVD) technique for CNF synthesis was chosen for this study. Thermal CVD allows for gas flow through the SMM matrices during CNF synthesis. In essence, the thermal CVD setup was a high-temperature catalytic reactor with the SMM matrix positioned to act as a catalyst packed bed within the reactor (without any bypass). The flow of synthesis gas through the 
SMM matrix is very important for 3-dimensional synthesis of CNF within the SMM matrix.

In order to understand the effects of synthesis conditions on the nickel SMM matrices, it was necessary to remove the factor of high surface area of SMM matrices from the synthesis optimization studies for ease of analyses. This was done by using nickel foil (low surface area nickel catalyst) as a tool to simulate the surface of nickel microfibers within the SMM matrices. The use of nickel foil ensured that there was limited catalyst surface area, which made it possible to analyze the rate of reaction by easy gravimetric measurements. Therefore, optimization of CNF synthesis conditions was carried out on nickel foil (low surface area catalyst), and the optimized conditions were shown to translate to synthesis on SMM matrices (high surface area catalyst).

In this study, the CNF was synthesized using a thermal CVD setup with a quartz tube of $51 \mathrm{~mm}$ ID as the reactor in a Lindberg furnace (model number CF56822C). The flow rates of gases were controlled by Aalborg rotameters. Details of the thermal CVD setup have been described elsewhere [46]. The nickel foil sample was placed at the center of the reactor with its faces parallel to the direction of flow for equal exposure of gases to both faces of the foil. The sample was supported at two edges by layers of quartz wool. The temperature inside the reactor was verified prior to experiments using a thermocouple inserted in the position of the sample.

The approach taken to increase the yield of CNF was the thermal redox faceting pretreatment of nickel substrates. Nickel foil was degreased with acetone prior to all experiments. The reactor tube containing the sample was inserted in the furnace after the furnace reached the desired temperature. The reactor was kept under nitrogen flow for $15 \mathrm{~min}$, before the temperature ramp-up of the reactor and prior to pretreatment or synthesis, to prevent any high-temperature interaction of foil with residual oxygen. For faceting pretreatment, the degreased nickel foil samples $(25 \mathrm{~mm} \times 25 \mathrm{~mm})$ with a weight of $\sim 0.65 \mathrm{~g}$ were faceted at various temperatures by three cycles of oxidation (using $10 \%$ air in nitrogen) and reduction (using 10\% hydrogen in nitrogen); each cycle lasted for $11 \mathrm{~min}$. Nitrogen was passed for $1 \mathrm{~min}$ between the steps of oxidation $(5 \mathrm{~min})$ and reduction $(5 \mathrm{~min})$ to avoid the mixture of hydrogen and air at high temperatures. At the end of all pretreatment cycles, the samples were reduced (using 10\% hydrogen in nitrogen) for an additional $15 \mathrm{~min}$ to bring them to a metallic state. Samples, which were not faceted, were annealed at $715^{\circ} \mathrm{C}$ for $15 \mathrm{~min}$ in $10 \%$ hydrogen unless noted otherwise. The reactor was removed from the furnace after faceting/synthesis and cooled to ambient temperature under nitrogen flow. Typical cool down time was $\sim 10 \mathrm{~min}$.

The pretreated samples were used for univariant optimization of CNF synthesis parameters, as shown in Figure 3. Redox faceting pretreatment, synthesis temperature, and concentrations of hydrogen and ammonia were the parameters optimized for CNF synthesis. All the optimization studies were performed in absence of postsynthesis purification such as acid treatment. All the gases required for synthesis except acetylene were passed at desired concentrations through the reactor for $15 \mathrm{~min}$ prior to synthesis to ensure that all the catalyst surface-gas interactions were at steady state before the introduction of acetylene. The total flow rate of the synthesis gas was always maintained at $1070 \mathrm{sccm}$, and the flow of acetylene was maintained at $20 \mathrm{sccm}(\sim 2 \%)$. Synthesis time for all experiments with nickel foil was $10 \mathrm{~min}$ unless noted otherwise. All the experiments were performed at atmospheric pressure.

2.3. Characterization. The yield of carbon on the nickel substrates was determined gravimetrically. The morphology of the carbon deposit was characterized by JEOL 7000F scanning electron microscopy (SEM). A Renishaw InVia Raman spectrometer, in conjunction with SEM, provided a good estimate of the amount of amorphous carbon in the carbon deposit. The D/G ratio obtained from Raman spectroscopy is the ratio of $\mathrm{sp}^{3}$ to $\mathrm{sp}^{2}$ carbon in the sample. All the $D / G$ ratios calculated from Raman spectra were obtained using a $514 \mathrm{~nm}$ wavelength laser with a high signalto-noise ratio and baseline correction. The $\mathrm{D} / \mathrm{G}$ ratios were measured at 1-3 spots per sample with a minimum of 2 samples for each synthesis condition. Raman spectroscopy shows one number of the $\mathrm{D} / \mathrm{G}$ ratio for two characteristics of the carbon deposit. A high D/G ratio can be due to (a) a high fraction of $\mathrm{sp}^{3}$ carbon in CNF (also known as lattice defects in the graphene sheet) and/or (b) a high fraction of amorphous carbon. It is not possible to differentiate between the two distinct characteristics of the carbon deposit using only Raman spectroscopy. Therefore, Raman spectroscopy was used as a secondary characterization technique for carbon deposits. High-quality CNF is defined here as CNF with a very low quantity of amorphous carbon byproduct observed by SEM and a low D/G ratio in Raman spectroscopy. Other supplementary characterization technique used was transmission electron microscope (TEM).

\section{Results and Discussion}

3.1. Hydrocarbon for Carbon Nanofiber (CNF) Synthesis. It has been reported that the unsaturated hydrocarbons undergo rapid catalytic decomposition over transition metals at high temperatures [3]. Also acetylene (ethyne) has been found to decompose faster than alkanes and alkenes [3]. Therefore, acetylene was chosen as the carbon source for synthesis because it is the smallest unsaturated hydrocarbon molecule and because examples of successful CNF synthesis using acetylene abound in the literature.

3.2. Effects of Pretreatment. Catalyst activity has been shown to increase in the presence of grain boundaries or surface roughness [3, 30, 42, 47-49]. From a few preliminary experiments, a synthesis temperature of $470^{\circ} \mathrm{C}$ with $10 \%$ hydrogen in nitrogen as the carrier gas was found to be the lowest temperature at which the CNF could be synthesized on nickel foil. The different pretreatment conditions tested and their effects on the carbon yield are shown in Table 1 (Phase 1) for $\mathrm{CNF}$ synthesis at $470^{\circ} \mathrm{C}$. The "as-received" nickel foil had the least carbon yield after synthesis. This 
TABLE 1: Sequence of CNF synthesis optimization efforts on nickel foil substrates.

\begin{tabular}{|c|c|c|c|c|c|c|c|c|}
\hline \multirow{2}{*}{$\begin{array}{l}\text { Phase } \\
\text { number }\end{array}$} & \multirow{2}{*}{$\begin{array}{l}\text { Phases } \\
\text { Description of phase }\end{array}$} & \multicolumn{4}{|c|}{ Experimental details* } & \multicolumn{3}{|c|}{ Results } \\
\hline & & Substrate pretreatment & $\begin{array}{l}\mathrm{H}_{2} \\
(\%)\end{array}$ & $\begin{array}{l}\mathrm{NH}_{3} \\
(\%)\end{array}$ & $\begin{array}{c}\mathrm{T} \\
\left({ }^{\circ} \mathrm{C}\right)\end{array}$ & $\begin{array}{c}\text { Raman } \\
(\mathrm{D} / \mathrm{G} \text { ratio })( \pm 0.02)\end{array}$ & $\begin{array}{c}\text { Carbon yield } \\
\text { (mg C/g Ni foil) } \\
( \pm 6 \%)\end{array}$ & $\begin{array}{l}\text { Supporting SEM } \\
\text { (figure number) }\end{array}$ \\
\hline \multirow{6}{*}{1} & \multirow{6}{*}{$\begin{array}{l}\text { Effects of substrate } \\
\text { pretreatment }\end{array}$} & As-received & \multirow{6}{*}{10} & \multirow{6}{*}{0} & \multirow{6}{*}{470} & 0.96 & 10 & $4 \mathrm{~A}$ and $5 \mathrm{~A}$ \\
\hline & & $\begin{array}{l}\text { Reduction at } 715^{\circ} \mathrm{C} \text { for } \\
15 \mathrm{~min}\end{array}$ & & & & 1.06 & 16 & $4 \mathrm{~B}$ and $5 \mathrm{~B}$ \\
\hline & & $\begin{array}{l}\text { Reduction at } 815^{\circ} \mathrm{C} \text { for } \\
120 \mathrm{~min}\end{array}$ & & & & 1.04 & 17 & $4 \mathrm{C}$ and $5 \mathrm{C}$ \\
\hline & & Thermal faceting at $515^{\circ} \mathrm{C}$ & & & & 1.06 & 21 & $4 \mathrm{D}$ and $5 \mathrm{D}$ \\
\hline & & Thermal faceting at $715^{\circ} \mathrm{C}$ & & & & 1.07 & 69 & $4 \mathrm{E}$ and $5 \mathrm{E}$ \\
\hline & & Thermal faceting at $815^{\circ} \mathrm{C}$ & & & & 1.14 & 82 & $4 \mathrm{~F}$ and $5 \mathrm{~F}$ \\
\hline \multirow{6}{*}{2} & \multirow{6}{*}{$\begin{array}{l}\text { Effects of CNF } \\
\text { synthesis temperature } \\
\text { (following Phase 1) }\end{array}$} & \multirow{6}{*}{ Thermal faceting at $815^{\circ} \mathrm{C}$} & \multirow{6}{*}{10} & \multirow{6}{*}{0} & 420 & - & 3 & $6 \mathrm{~A}$ \\
\hline & & & & & 470 & 1.14 & 82 & $6 \mathrm{~B}$ \\
\hline & & & & & 520 & 1.19 & 102 & $6 \mathrm{C}$ \\
\hline & & & & & 570 & 1.31 & 44 & $6 \mathrm{D}$ \\
\hline & & & & & 670 & 0.93 & 2 & $6 \mathrm{E}$ \\
\hline & & & & & 770 & - & 8 & $6 \mathrm{~F}$ \\
\hline \multirow{4}{*}{$3 \mathrm{~A}$} & \multirow{4}{*}{$\begin{array}{l}\text { Effects of hydrogen } \\
\text { concentration } \\
\text { (following Phase 2) }\end{array}$} & \multirow{4}{*}{ Thermal faceting at $815^{\circ} \mathrm{C}$} & 0 & \multirow{4}{*}{0} & \multirow{4}{*}{520} & - & 5 & - \\
\hline & & & 10 & & & 1.19 & 102 & - \\
\hline & & & 30 & & & 0.97 & 136 & - \\
\hline & & & 98 & & & 0.84 & 150 & - \\
\hline \multirow{8}{*}{$3 \mathrm{~B}$} & \multirow{8}{*}{$\begin{array}{l}\text { Verify optimal CNF } \\
\text { synthesis temperature } \\
\text { (following Phase } 3 \mathrm{~A} \text { ) }\end{array}$} & & & & 420 & - & 0 & - \\
\hline & & & & & 470 & 0.75 & 17 & $7 \mathrm{~A}$ \\
\hline & & & & & 520 & 0.84 & 150 & $7 \mathrm{~B}$ \\
\hline & & Thermal faceting at $815^{\circ} \mathrm{C}$ & 98 & 0 & 570 & 0.9 & 179 & 7C \\
\hline & & & & & 620 & 1.11 & 177 & $7 \mathrm{D}$ \\
\hline & & & & & 670 & 1.49 & 108 & $7 \mathrm{E}$ \\
\hline & & & & & 720 & - & 3 & $7 \mathrm{~F}$ \\
\hline & & & & & 770 & - & 0 & - \\
\hline & & & & & 420 & - & 0 & - \\
\hline & & & & & 470 & 0.64 & 7 & - \\
\hline & Verify effects of & & & & 520 & 0.82 & 48 & - \\
\hline $3 \mathrm{C}$ & substrate & Reduction at $715^{\circ} \mathrm{C}$ for & 98 & 0 & 570 & 0.80 & 123 & - \\
\hline & $\begin{array}{l}\text { pretreatment } \\
(\text { following Phase } 3 \mathrm{~A})\end{array}$ & $15 \mathrm{~min}$ & & & 620 & 0.97 & 51 & - \\
\hline & & & & & 670 & 1.15 & 36 & - \\
\hline & & & & & 720 & - & 3 & - \\
\hline & & & & & 770 & - & 3 & - \\
\hline & & & 98 & 0 & & 0.9 & 179 & $8 \mathrm{~A}$ \\
\hline & Effects of ammonia & & 78 & 20 & & 0.92 & 164 & $8 \mathrm{~B}$ \\
\hline $4 \mathrm{~A}$ & concentration & Thermal faceting at $815^{\circ} \mathrm{C}$ & 48 & 50 & 570 & 1 & 154 & $8 \mathrm{C}$ \\
\hline & (following Phase 3B) & & 18 & 80 & & 0.99 & 36 & $8 \mathrm{D}$ \\
\hline & & & 0 & 98 & & - & 1 & $8 \mathrm{E}$ \\
\hline & & & & & 520 & 0.77 & 130 & $9 \mathrm{~A}$ \\
\hline & & & & & 570 & 0.92 & 164 & $9 \mathrm{~B}$ \\
\hline & & & & & 620 & 1.14 & 162 & $9 \mathrm{C}$ \\
\hline & $\begin{array}{l}\text { Verify } 570^{\circ} \mathrm{C} \text { is } \\
\text { optimal CNF }\end{array}$ & & & & 670 & - & 9 & - \\
\hline $4 \mathrm{~B}$ & synthesis temperature & Thermal faceting at $815^{\circ} \mathrm{C}$ & 78 & 20 & 720 & - & 2 & - \\
\hline & (following Phase 4A) & & & & 770 & - & 4 & - \\
\hline & & & & & 820 & - & 3 & - \\
\hline & & & & & 870 & - & 2 & - \\
\hline & & & & & 920 & - & 3 & - \\
\hline
\end{tabular}


Table 1: Continued.

\begin{tabular}{|c|c|c|c|c|c|c|c|c|}
\hline \multirow[b]{2}{*}{$\begin{array}{l}\text { Phase } \\
\text { number }\end{array}$} & \multirow{2}{*}{$\begin{array}{l}\text { Phases } \\
\text { Description of phase }\end{array}$} & \multicolumn{4}{|c|}{ Experimental details* } & \multicolumn{3}{|c|}{ Results } \\
\hline & & Substrate pretreatment & $\begin{array}{l}\mathrm{H}_{2} \\
(\%)\end{array}$ & $\begin{array}{r}\mathrm{NH}_{3} \\
(\%)\end{array}$ & $\begin{array}{c}\mathrm{T} \\
\left({ }^{\circ} \mathrm{C}\right)\end{array}$ & $\begin{array}{c}\text { Raman } \\
(\mathrm{D} / \mathrm{G} \text { ratio })( \pm 0.02)\end{array}$ & $\begin{array}{c}\text { Carbon yield } \\
\text { (mg C/g Ni foil) } \\
( \pm 6 \%)\end{array}$ & $\begin{array}{l}\text { Supporting SEM } \\
\text { (figure number) }\end{array}$ \\
\hline \multirow{3}{*}{$4 \mathrm{C}$} & \multirow{3}{*}{$\begin{array}{l}\text { Verify effects of } \\
\text { substrate } \\
\text { pretreatment } \\
\text { (following Phase } 4 \mathrm{~A} \text { ) }\end{array}$} & $\begin{array}{c}\text { Reduction at } 715^{\circ} \mathrm{C} \text { for } \\
15 \mathrm{~min}\end{array}$ & \multirow{3}{*}{78} & \multirow{3}{*}{20} & \multirow{3}{*}{570} & - & 68 & $10 \mathrm{~A}$ \\
\hline & & Thermal faceting at $815^{\circ} \mathrm{C}$ & & & & 0.92 & 164 & 10B.1 \\
\hline & & - & & & & - & - & - \\
\hline
\end{tabular}

*Nitrogen used as inert diluent and 2\% acetylene for CNF synthesis.

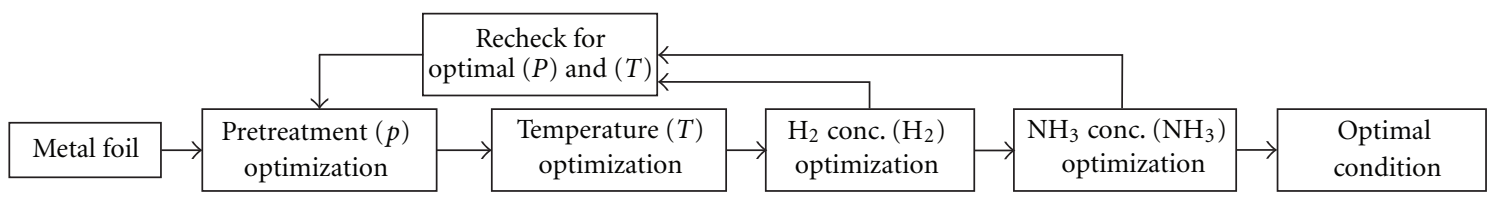

FiguRE 3: Univariant optimization experimental design for CNF synthesis.

low carbon yield could be due to the oxide layer on the "asreceived" nickel foil catalyst, which suppressed the formation of carbon product $[37,50,51]$. It has been reported that reduction of the catalyst before synthesis increases the carbon yield [30, 37, 47, 52]. The increase in carbon yield after reduction of the catalyst was also observed in this study, as shown in Table 1 (Phase 1). The samples reduced at $715^{\circ} \mathrm{C}$ for $15 \mathrm{~min}$ and $815^{\circ} \mathrm{C}$ for $120 \mathrm{~min}$ (using $10 \%$ hydrogen) had similar carbon yields (Table 1 (Phase 1)) and similar morphology of the carbon deposit; also, the deposits had similar D/G ratios in Raman spectroscopy (Table 1 (Phase 1)). It was thus deduced that reduction at $715^{\circ} \mathrm{C}$ for $15 \mathrm{~min}$ was sufficient to remove the oxide layer of the "as-received" foil. Nanoparticles were not formed (as observed by SEM) after the reduction of nickel foil at high temperatures, which is unlike the observations reported by Jeong et al. [25]. The carbon yield increased with the increase in the redox faceting temperature (Table 1 (Phase 1)). The maximum carbon yield was $82 \mathrm{mg} /\left(\mathrm{g}\right.$ of foil) for the $815^{\circ} \mathrm{C}$ faceted sample at synthesis temperature of $470^{\circ} \mathrm{C}$ with $2 \%$ acetylene, $10 \%$ hydrogen, and $88 \%$ nitrogen.

The yield of carbon for each pretreatment condition in Table 1 (Phase 1) can be correlated to the SEM images of the pretreated samples shown in Figure 4. The faceting pretreatment added grain boundaries to the foil and increased the carbon yield. The number of grain boundaries increased progressively with the faceting pretreatment temperature. Distinct facets and maximum grain boundaries were observed for the $815^{\circ} \mathrm{C}$ faceted sample, which also had the maximum yield as shown in Table 1 (Phase 1 ).

The SEM images of synthesized CNF on pretreated foil are shown in Figure 5. As expected, the CNF in the deposit had variations in diameter because the catalyst particle size could not be controlled. The deposit on the "asreceived" foil had less amorphous carbon. The synthesis on samples reduced at $715^{\circ} \mathrm{C}$, and $815^{\circ} \mathrm{C}$ had some amorphous carbon associated with it. After faceting pretreatment, the amorphous content of the deposit increased and was maximized for samples faceted at $815^{\circ} \mathrm{C}$ (Figure 5(f)). The high amorphous content on $815^{\circ} \mathrm{C}$ faceted foil was also seen by Raman spectroscopy in the form of the highest $D / G$ ratio (Table 1 (Phase 1)).

It was found that synthesis temperature of $470^{\circ} \mathrm{C}$ with $10 \%$ hydrogen in nitrogen as the carrier gas gave the least rate of reaction with CNF formation and low amorphous carbon for "as-received" and reduced nickel foil samples. This synthesis condition was taken as the optimal condition for the minimum rate of reaction for 3-dimensional deposition of CNF within the nonfaceted sintered metal microfibrous (SMM) matrix. For a high rate of reaction, of all the pretreatment conditions tested, the $815^{\circ} \mathrm{C}$ faceting pretreatment was taken to be the optimal pretreatment condition for maximizing the carbon yield. Also, the optimal faceting pretreatment condition (faceting at $815^{\circ} \mathrm{C}$ ) did not change with the temperatures and gas compositions used for CNF synthesis. As seen in Figure 5(f), the quality of CNF for the $815^{\circ} \mathrm{C}$ faceted sample was the worst among all the samples tested. Further studies on $815^{\circ} \mathrm{C}$ faceted nickel foil were pursued in an attempt to enhance the yield and quality of CNF.

3.3. Effects of Synthesis Temperature. After optimizing pretreatment of foil to faceting at $815^{\circ} \mathrm{C}$ for a high carbon yield, the effect of temperature on synthesis was studied to further increase the yield and quality of CNF. As shown in Table 1 (Phase 2), the temperature of synthesis for maximum carbon yield was $520^{\circ} \mathrm{C}$. At a synthesis temperature of $570^{\circ} \mathrm{C}$, the carbon deposit contained only large diameter CNF of the order of 300-600 nm (dia.) as shown in Figure 6(d). That sample had a very high D/G ratio (Table 1 (Phase 2)) in Raman spectroscopy, which indicated high $\mathrm{sp}^{3}$ carbon fraction within the CNF. There were no CNF observed for synthesis temperature of $420^{\circ} \mathrm{C}, 670^{\circ} \mathrm{C}$, and $770^{\circ} \mathrm{C}$. The 


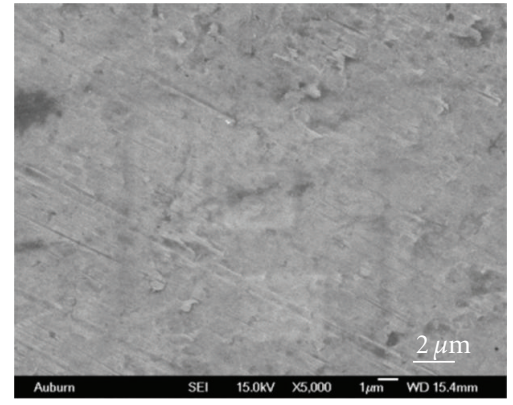

(a)

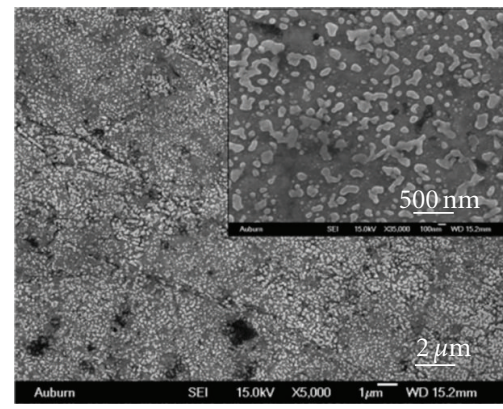

(d)

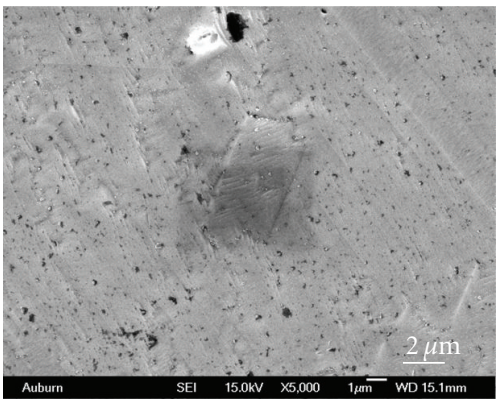

(b)

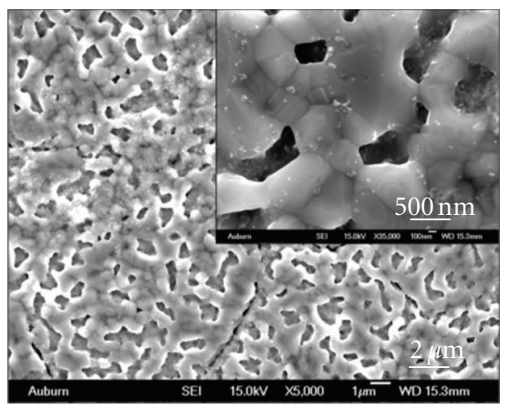

(e)

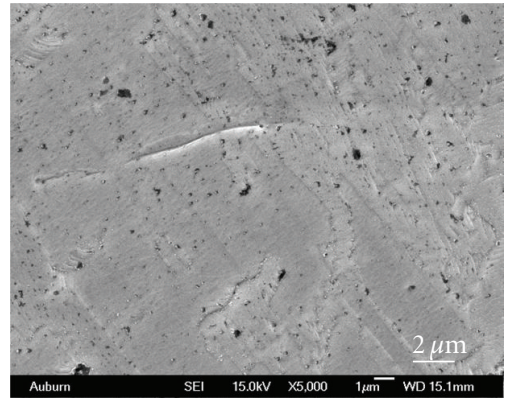

(c)

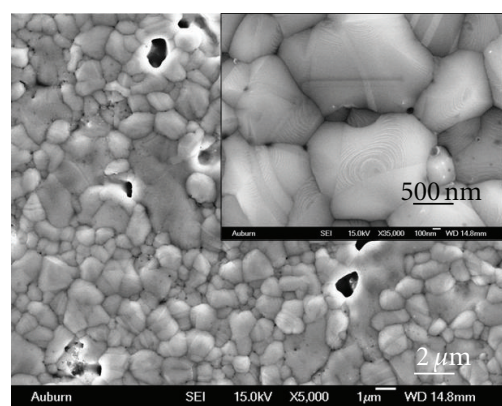

(f)

FIgURE 4: Effects of pretreatment on nickel foil: (a) as-received, (b) reduced at $715^{\circ} \mathrm{C}$ for $15 \mathrm{~min}$, (c) reduced at $815^{\circ} \mathrm{C}$ for $120 \mathrm{~min}$, (d) thermal faceting at $515^{\circ} \mathrm{C}$, (e) thermal faceting at $715^{\circ} \mathrm{C}$, and (f) thermal faceting at $815^{\circ} \mathrm{C}$ (Table 1 (Phase 1$)$ ).

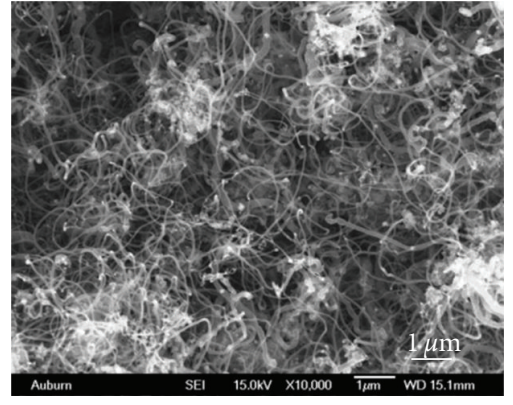

(a)

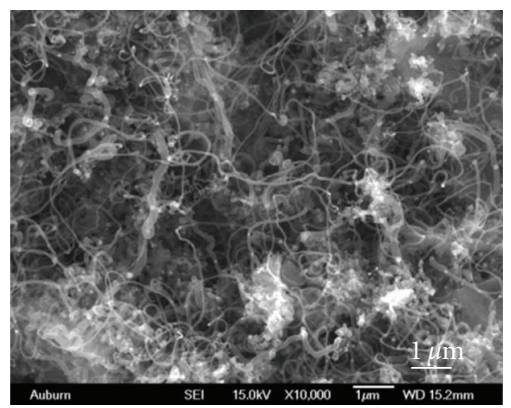

(d)

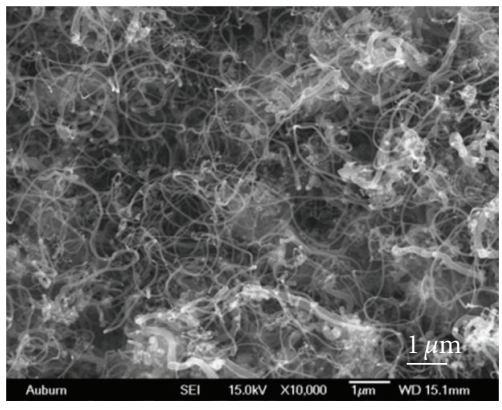

(b)

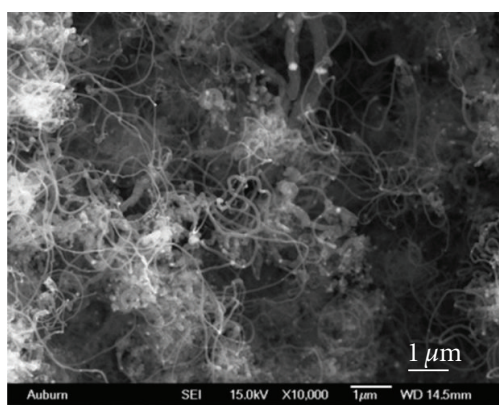

(e)

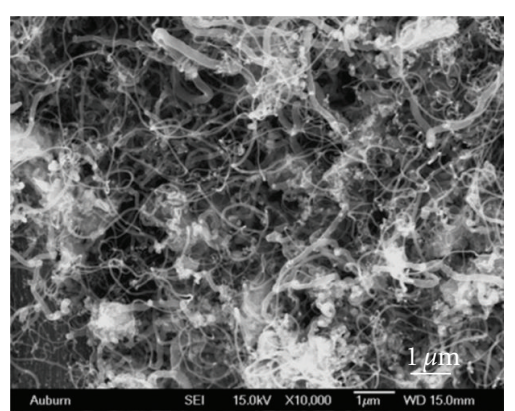

(c)

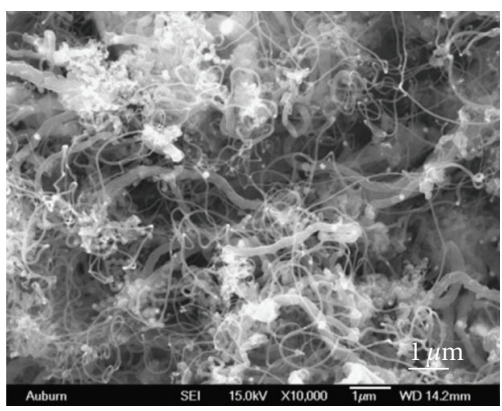

(f)

FIGURE 5: Synthesized CNF for effects of pretreatment on foil: (a) as-received, (b) reduced at $715^{\circ} \mathrm{C}$ for $15 \mathrm{~min}$, (c) reduced at $815^{\circ} \mathrm{C}$ for $120 \mathrm{~min}$, (d) thermal faceting at $515^{\circ} \mathrm{C}$, (e) thermal faceting at $715^{\circ} \mathrm{C}$, and (f) thermal faceting at $815^{\circ} \mathrm{C}$. Synthesis conditions: $2 \% \mathrm{C}_{2} \mathrm{H}_{2}$, $10 \% \mathrm{H}_{2}, 88 \% \mathrm{~N}_{2}$, and $470^{\circ} \mathrm{C}$ (Table 1 (Phase 1 )). 
temperature of $520^{\circ} \mathrm{C}$ was chosen for further experiments due to its high carbon yield.

3.4. Effects of Hydrogen in Synthesis Gas. The effects of varying concentration of hydrogen were studied to enhance the yield and quality of CNF. Hydrogen gas increases the carbon yield [30, 50, 52, 53] and keeps the catalyst active [54] during CNF synthesis by avoiding carbon encapsulation of the catalyst surface $[52,55]$. A higher yield of carbon above $450^{\circ} \mathrm{C}$ due to the presence of hydrogen has been reported in the kinetic studies of acetylene decomposition over nickel foil [50] and nichrome wire [5]. It has been reported that medium concentrations of hydrogen can promote the formation of CNF on the catalyst, while high concentrations of hydrogen can be inhibitory to the formation of CNF $[30,54]$. One reason stated is that very high concentrations of hydrogen can rapidly remove the carbon from the catalyst surface, preventing CNF or carbon nanotube (CNT) formation, while very low concentrations of hydrogen may lead to catalyst deactivation due to pyrolytic carbon buildup [30]. However, the effect of hydrogen may depend on the temperature of synthesis. At high temperatures $\left(>700^{\circ} \mathrm{C}\right)$, excess hydrogen has been reported to have a negative effect [36] as compared to the typical positive effect reported in the literature at lower temperatures $\left(<600^{\circ} \mathrm{C}\right)$ mentioned above. It should be noted that, at any temperature, synthesis with hydrogen in the synthesis gas will yield more carbon for a nickel catalyst as compared to synthesis in absence of hydrogen since hydrogen is required to keep the catalyst active [53]. It has been shown that, for a bulk nickel metal catalyst, the rate of carbon deposition increases with an increase in concentration of hydrogen in the acetylenehydrogen system at $608^{\circ} \mathrm{C}$ [53]. These synthesis parameters were very similar to the parameters used in this study.

For the temperature range of interest $\left(470^{\circ} \mathrm{C}-620^{\circ} \mathrm{C}\right)$, the increase in the concentration of hydrogen was expected to increase the carbon yield. This is shown in Table 1 (Phase $3 \mathrm{~A}$ ) for the synthesis temperature of $520^{\circ} \mathrm{C}$. The maximum yield of carbon was found at $98 \%$ hydrogen in synthesis gas. Following the univariant experimental design (Figure 3), experiments were carried out to verify whether the optimum temperature of synthesis in $98 \%$ hydrogen environment remained at $520^{\circ} \mathrm{C}$. The yield of carbon for $98 \%$ hydrogen synthesis at various temperatures is shown in Table 1 (Phase $3 \mathrm{~B})$. The temperature of maximum carbon yield changed from $520^{\circ} \mathrm{C}$ to $570^{\circ} \mathrm{C}$ with the change of hydrogen concentration from $10 \%$ to $98 \%$. This was attributed to the change in the activity of the catalyst for higher concentrations of hydrogen.

The decrease in $\mathrm{D} / \mathrm{G}$ ratio of Raman spectroscopy for 98\% hydrogen synthesis (Table 1 (Phase 3B)) as compared to $10 \%$ hydrogen synthesis (Table 1 (Phase 2)) showed that the fraction of $\mathrm{sp}^{3}$ carbon in $\mathrm{CNF}$ and/or amorphous carbon was reduced for $570^{\circ} \mathrm{C}$ synthesis. The SEM images (Figure 7) showed that the least amount of amorphous carbon was present in the sample synthesized at $570^{\circ} \mathrm{C}$ which also had the maximum carbon yield (Table 1 (Phase 3B)). Out of all the conditions tested in this study, the $570^{\circ} \mathrm{C}$ synthesis with $98 \%$ hydrogen on $815^{\circ} \mathrm{C}$ faceted nickel foil resulted in maximum carbon yield. The carbon yield achieved at these synthesis conditions was $60 \%$. However, the carbon yield may have been limited by the supply of acetylene rather than the catalytic activity of the foil. The face velocity of gas within the reactor at $570^{\circ} \mathrm{C}$ reaction temperature was $22 \mathrm{~mm} / \mathrm{s}$, and the $25 \mathrm{~mm} \times 25 \mathrm{~mm}$ sample was placed at the center of $51 \mathrm{~mm}$ diameter reactor with faces parallel to the direction of flow. The void space of the reactor near the foil may have caused bypassing of gases, resulting in limited carbon yield on nickel foil. It is interesting to note that $670^{\circ} \mathrm{C}$ synthesis (Figure 7(e)) had distinct CNF with little amorphous carbon as seen in the SEM images, but it had a very high $D / G$ ratio in Raman spectroscopy (Table 1 (Phase 3B)). It can be concluded that the $\mathrm{sp}^{3}$ carbon within the CNF was very high with little or no amorphous carbon for the $670^{\circ} \mathrm{C}$ synthesis.

Following the univariant experimental design (Figure 3), similar temperature optimization experiments were carried out for $715^{\circ} \mathrm{C}$ reduced foil (nonfaceted) to ensure that faceting was indeed an important independent variable which affected the yield of carbon, and it was not overshadowed by the increase in yield due to high fraction of hydrogen $(98 \%)$. The carbon yields on the $715^{\circ} \mathrm{C}$ reduced foil at various temperatures with $98 \%$ hydrogen are shown in Table 1 (Phase 3C). The maximum yield for these nonfaceted samples was also found to be at a temperature of $570^{\circ} \mathrm{C}$. However, comparing the carbon yield in Table 1 (Phase $3 \mathrm{~B}$ ) and (Phase 3C), the yield of the $815^{\circ} \mathrm{C}$ faceted sample was $46 \%$ higher than that of the $715^{\circ} \mathrm{C}$ reduced sample. This proved that faceting pretreatment was an independent parameter for enhancement of carbon yield. As there was less amorphous carbon and maximum carbon yield for CNF synthesized at $570^{\circ} \mathrm{C}$ on $815^{\circ} \mathrm{C}$ faceted foil with $2 \%$ acetylene and $98 \%$ hydrogen, it was taken as the optimal synthesis condition for further studies.

3.5. Effects of Ammonia in Synthesis Gas. Ammonia pretreatment [56-58] and synthesis in ammonia environment [5961] have been investigated by a few researchers for synthesis of aligned CNF/CNT. It has been proposed that ammonia helps in formation of high density of nucleation sites on the catalyst for CNF/CNT synthesis and prevents catalyst passivation by removing amorphous carbon in the initial stages of synthesis $[23,56]$. Also, researchers have shown that ammonia can keep the catalyst active resulting in higher carbon yield as compared to synthesis with hydrogen at temperatures above $750^{\circ} \mathrm{C}[56,62,63]$. Some researchers have proposed that atomic hydrogen [56] and/or atomic nitrogen [63] produced by the catalytic decomposition of ammonia keeps the catalyst active at high temperatures for synthesis of aligned CNF. Also, there are conflicting observations for the need of ammonia during synthesis of aligned CNF with some researchers proposing that ammonia is required only for the initial stage of synthesis [23] while some others proposing that ammonia is required during synthesis $[56,61,64]$. There are very few reports of aligned CNF on bulk nickel metal either with [60] or without ammonia [65]. However, these researchers used plasmaenhanced CVD at low pressures of 1-20 torr. Bower et al. 


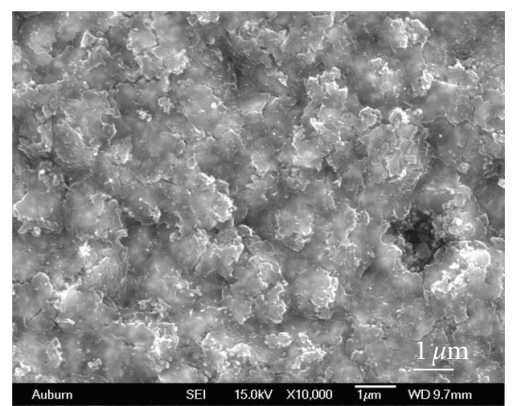

(a)

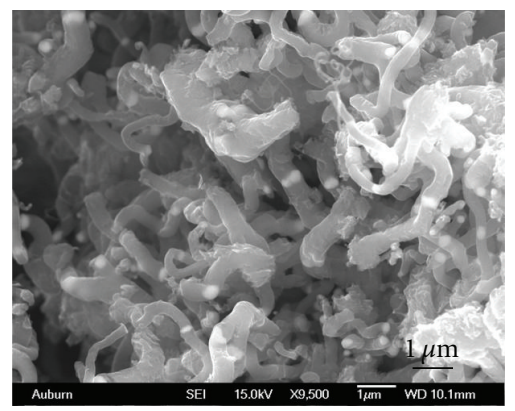

(d)

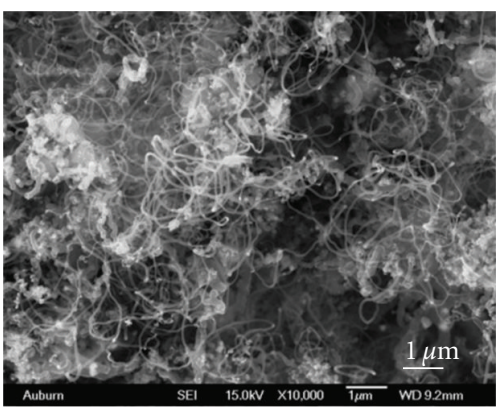

(b)

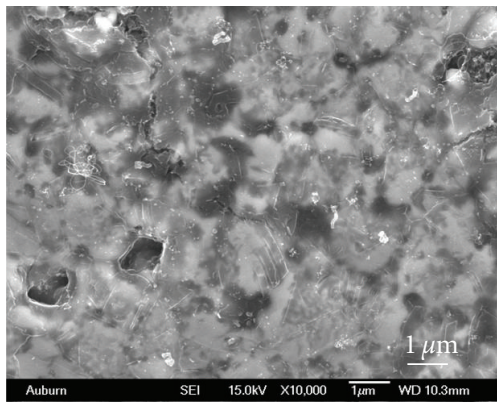

(e)

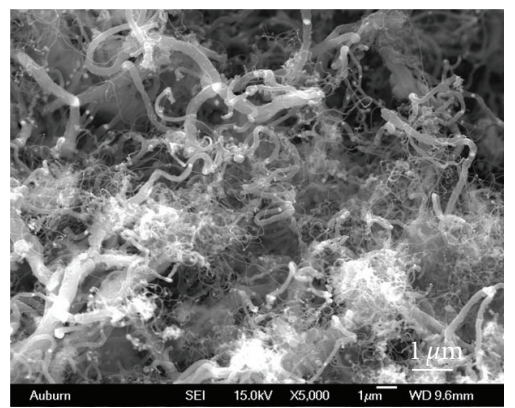

(c)

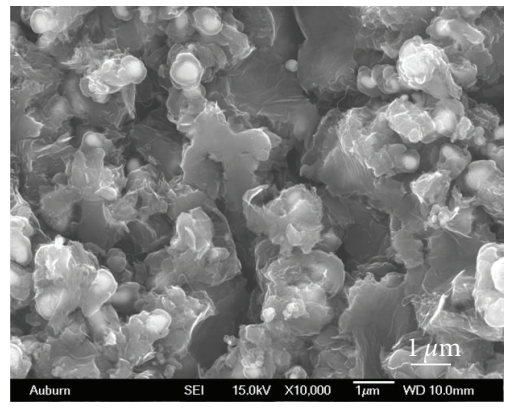

(f)

Figure 6: CNF growth in $10 \% \mathrm{H}_{2}\left(2 \% \mathrm{C}_{2} \mathrm{H}_{2}, 88 \% \mathrm{~N}_{2}\right.$ ). Temperature: (a) $420^{\circ} \mathrm{C}$, (b) $470^{\circ} \mathrm{C}$, (c) $520^{\circ} \mathrm{C}$, (d) $570^{\circ} \mathrm{C}$, (e) $670^{\circ} \mathrm{C}$, and (f) $770^{\circ} \mathrm{C}$. Sample faceted at $815^{\circ} \mathrm{C}$ (Table 1 (Phase 2)).

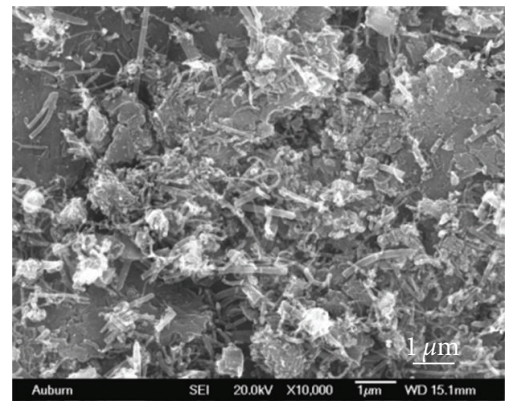

(a)

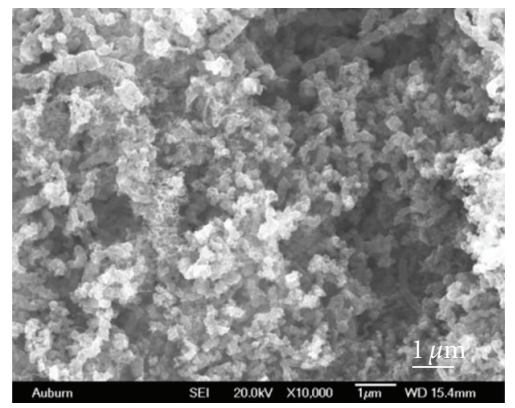

(d)

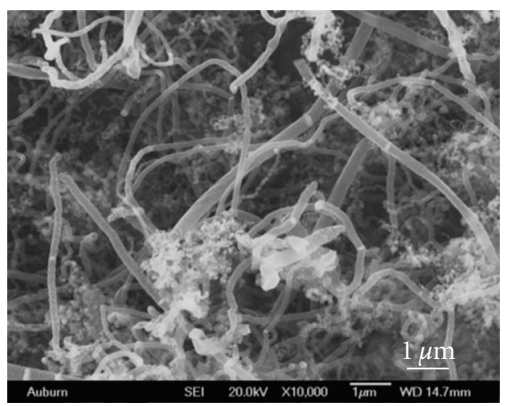

(b)

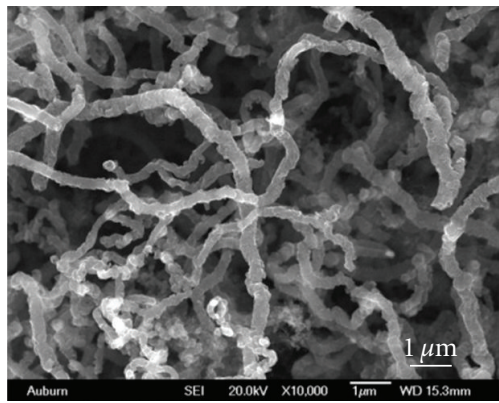

(e)

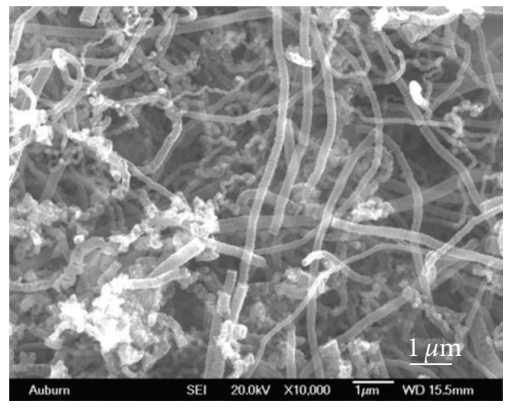

(c)

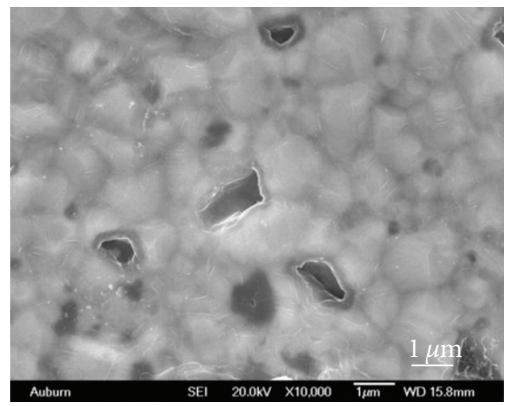

(f)

Figure 7: CNF growth in $98 \% \mathrm{H}_{2}\left(2 \% \mathrm{C}_{2} \mathrm{H}_{2}\right)$. Temperature: (a) $470^{\circ} \mathrm{C}$, (b) $520^{\circ} \mathrm{C}$, (c) $570^{\circ} \mathrm{C}$, (d) $620^{\circ} \mathrm{C}$, (e) $670^{\circ} \mathrm{C}$, and (f) $720^{\circ} \mathrm{C}$. Sample faceted at $815^{\circ} \mathrm{C}$ (Table 1 (Phase $\left.3 \mathrm{~B}\right)$ ). 
reported that plasma enhanced CVD technique is the reason for the alignment because ferromagnetic catalysts such as nickel, cobalt, or iron are oriented due to the electric field [66]. Therefore, it was not clear whether ammonia or the synthesis technique was responsible for the alignment. In this study, attempts were made to align CNF on faceted nickel foil using ammonia in thermal CVD synthesis at atmospheric pressures.

Varying the ammonia concentration in synthesis gas between $0 \%$ and $98 \%$ had no discernible effect on the orientation of CNF. The carbon yields for various concentrations of ammonia in synthesis gas at $570^{\circ} \mathrm{C}$ synthesis temperature are shown in Table 1 (Phase 4A). As ammonia concentration increased, the yield of carbon progressively decreased. At 20\% ammonia, the amorphous carbon in the deposit decreased significantly (Figure $8(\mathrm{~b})$ ). Figures $8(\mathrm{c})$, $8(\mathrm{~d})$, and $8(\mathrm{e})$ show the degradation of quality of the carbon deposit for ammonia concentrations greater than $20 \%$. Therefore, $20 \%$ ammonia in synthesis gas was the optimum condition for least amount of amorphous carbon and high carbon yield at $570^{\circ} \mathrm{C}$. The high $\mathrm{D} / \mathrm{G}$ ratio in Table 1 (Phase $4 \mathrm{~A}$ ) also indicated the degeneration of quality of the carbon deposit for ammonia concentrations greater than $20 \%$.

Few researchers have used ammonia at high temperatures $\left(>700^{\circ} \mathrm{C}\right.$ ) for alignment of $\mathrm{CNF} / \mathrm{CNT}$ using thermal CVD technique on different catalyst configurations [23, 56, 67]. Therefore, a synthesis temperatures range of $520-920^{\circ} \mathrm{C}$ was probed with $20 \%$ ammonia as shown in Table 1 (Phase 4B). There was no improvement in alignment or carbon yield at temperatures higher than $570^{\circ} \mathrm{C}$, and the nickel foil became catalytically inactive at temperatures greater than $670^{\circ} \mathrm{C}$. Solid carbon deposits were found on the walls of the reactor above $800^{\circ} \mathrm{C}$. This was attributed to the high rate of self-decomposition of acetylene above $700^{\circ} \mathrm{C}$ [68]. Following the univariant optimization experimental design (Figure 3), Table 1 (Phase 4B) shows that the temperature of maximum carbon yield remained at $570^{\circ} \mathrm{C}$ after addition of $20 \%$ ammonia in synthesis gas. Also, the SEM images (Figure 9) showed that the synthesis temperature for best morphology of the carbon deposit remained at $570^{\circ} \mathrm{C}$.

Following univariant optimization experimental design (Figure 3), CNF synthesis was done on both faceted foil and nonfaceted foil to verify that the faceting pretreatment gave the best yield and quality of CNF. As shown in Figure 10, the morphology of the deposit for $815^{\circ} \mathrm{C}$ faceted foil (Figure 10(b)) was better than that for $715^{\circ} \mathrm{C}$ annealed foil (Figure 10(a)) for the same synthesis temperature. Although ammonia did not assist in CNF orientation, it reduced the amorphous carbon of the deposit for faceted samples. Figure 10(b2) shows the TEM image of CNF synthesized on faceted samples at optimal conditions ( $20 \%$ ammonia). This shows that the CNF is made from stacks of carbon blocks. These carbon blocks probably have "platelet" orientation of graphene sheets as they were not hollow in the center; therefore, the term "nanofiber" was used to describe results of this study which encompasses all forms of nanofibers including nanotubes which are hollow in the center. For high yield and quality of CNF, the optimal synthesis condition was found to be $20 \%$ ammonia, $78 \%$ hydrogen, and $2 \%$ acetylene at a $570^{\circ} \mathrm{C}$ synthesis temperature. This synthesis condition was taken as the optimal condition for high rate of reaction for surface deposition of CNF on the nickel SMM matrices.

3.6. Synthesis of CNF within Nickel Sintered Metal Microfibrous (SMM) Matrices. Optimization of CNF synthesis on nickel foil was studied with the aim of finding the synthesis conditions for 3-dimensional (low rate of reaction) and surface (high rate of reaction) deposition of CNF within the SMM matrices. Figure 11 shows the SEM images of the 3-dimensional deposition of CNF within the SMM matrix using the synthesis conditions optimized in this study for a low rate of reaction. Figures $11(\mathrm{a})$ and 11(b) show the SEM images of SMM matrix before and after $11 \mathrm{~min}$ synthesis, respectively [46]. Figures 11(c1), 11(c2), and 11(c3) show that the CNF is uniformly deposited throughout the thickness of the SMM matrix [46]. These matrices with 3-dimensional deposition of CNF have shown enhancement in air filtration performance due to CNF synthesis [46]. Figure 12 shows the SEM images of surface deposition of CNF on the SMM matrix using synthesis conditions optimized for a high rate of reaction. Figures 12 (a) and 12(b1) show the SMM matrix before and after redox faceting pretreatment. Figure 12(c1) shows the cross-sectional view of SMM matrix after $11 \mathrm{~min}$ synthesis of CNF. Figures 12(c2) and 12 (c3) clearly show that the CNF is densely synthesized only on the surface of the SMM matrix and the CNF is not synthesized throughout the thickness of the SMM matrix. Figure 11 corresponds to the schematic diagram Figure 2(b), and Figure 12 corresponds to Figure 2(a).

3.7. Mechanism of CNF Synthesis. The basic steps in the mechanism of synthesis of CNF involve adsorption and catalytic decomposition of hydrocarbon gas to yield atomic carbon on the catalyst surface. The carbon atoms are transported to active catalyst sites by surface diffusion [1] and/or bulk diffusion [55], where the synthesis occurs. The rate determining step for CNF synthesis is reported to be the diffusion of carbon over/through the catalyst $[50,52,55]$. Typically, three periods are observed in the synthesis of CNF: (a) incubation period, (b) constant synthesis rate period and (c) tailing off period $[50,52]$. Finally, the reaction stops because of catalyst poisoning due to deviation from the reaction equilibrium which coats the catalyst particle with a carbon layer $[52,55]$. The incubation period at atmospheric pressures is not significant for acetylene decomposition on nickel [3]. In this study, all experiments were performed in the constant synthesis rate period as observed in Figure 13 for faceted and nonfaceted foil. The experimental errors involved in this study prevented detection of an incubation period of synthesis. Also, a tail off period was not observed due to the short synthesis times (10-15 min).

Formation of small catalyst crystallites is necessary for the synthesis of CNF, as they are known to be the source of CNF growth. These crystallites are formed during the incubation period of the synthesis process. The faceting pretreatment optimized in this study added grain boundaries 


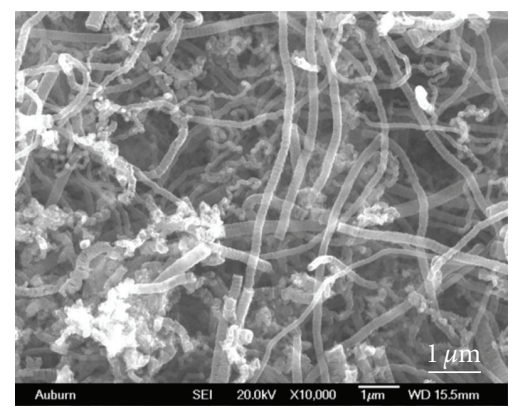

(a)

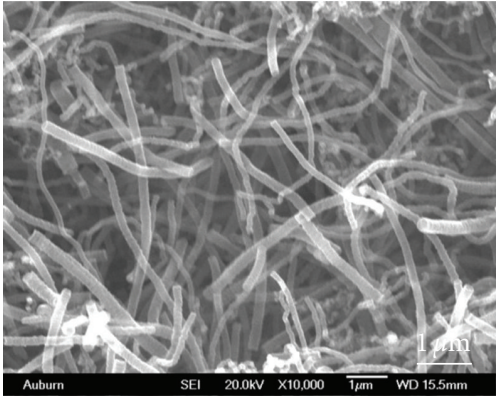

(b)

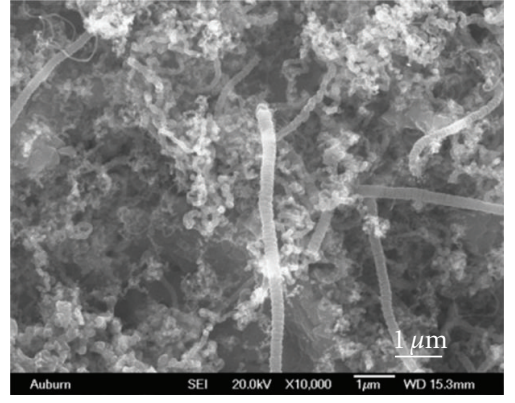

(c)

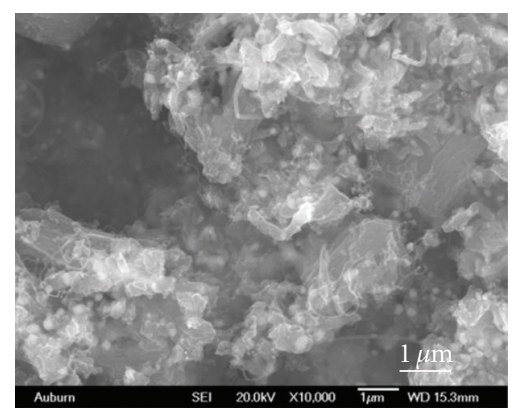

(d)

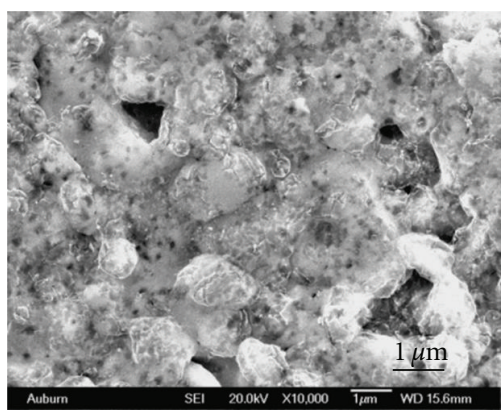

(e)

Figure 8: Synthesized CNF for effects of $\mathrm{NH}_{3}$ during synthesis on $815^{\circ} \mathrm{C}$ faceted foil. $\mathrm{NH}_{3}$ concentration: (a) $0 \%$, (b) $20 \%$, (c) $50 \%$, (d) $80 \%$, and (e) $98 \%$. Synthesis conditions: $570^{\circ} \mathrm{C}, 2 \% \mathrm{C}_{2} \mathrm{H}_{2}$, and remainder $\mathrm{H}_{2}$ (Table 1 (Phase $\left.4 \mathrm{~A}\right)$ ).

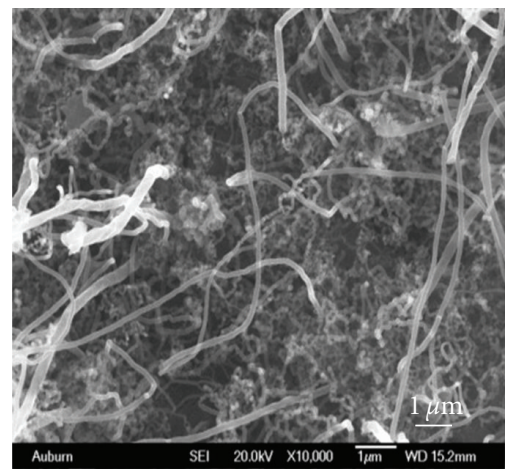

(a)

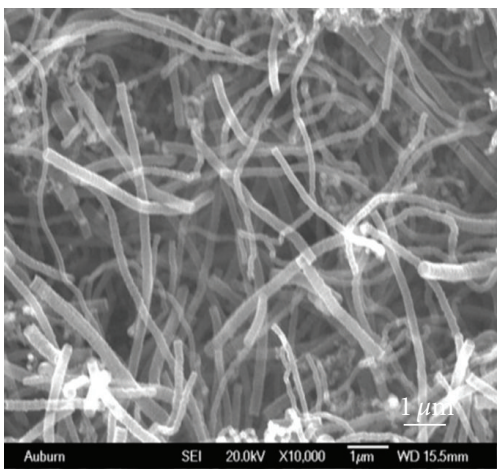

(b)

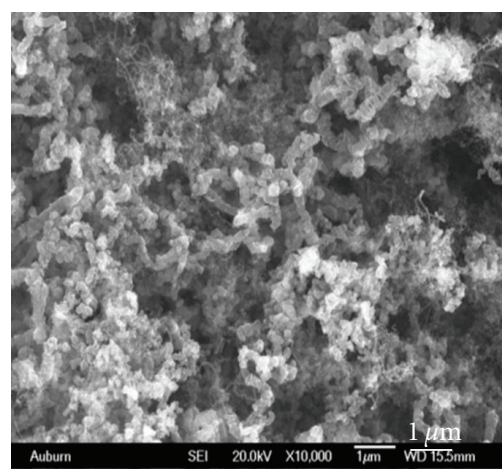

(c)

Figure 9: Synthesized CNF for effect of synthesis temperature on $815^{\circ} \mathrm{C}$ faceted foil. Temperature: (a) $520^{\circ} \mathrm{C},\left(\right.$ b) $570^{\circ} \mathrm{C}$, and (c) $620^{\circ} \mathrm{C}$. Synthesis gas: $2 \% \mathrm{C}_{2} \mathrm{H}_{2}, 20 \% \mathrm{NH}_{3}$, and $78 \% \mathrm{H}_{2}$ (Table 1 (Phase $4 \mathrm{~B}$ )).

to the nickel catalyst. It has been previously reported that the grain boundaries on bulk metals act as nucleation sites [3, 47] due to change in local topography and/or effect of local impurities [69]. Also, grain boundaries provide a fast path for mass transport [39]. The enhanced mass transport into faceted nickel foil accelerated the formation of crystallites, which resulted in the increase in carbon yield.

Figueredo et al. reported that hydrogen does not affect the CNF synthesis on supported nickel catalyst, but it affects synthesis on bulk nickel metal by helping in initial crystallite formation and enhancing the process of nucleation of carbon at the grain boundaries [2]. The higher carbon yield on foil for higher hydrogen concentrations may have been due to the combination of accelerated crystallite formation [2] and maintaining the nickel catalyst activity $[52,55,70]$. Ammonia decomposes over the nickel catalyst at experimental conditions close to those used in this study [71]. Also, Shalagina et al. concluded that ammonia in synthesis gas significantly changed the CNF morphology and the quantity of nitrogen in CNF [72]. We hypothesize that the endothermic decomposition of ammonia may change the catalyst characteristics for the exothermic acetylene decomposition during CNF synthesis. It has also been proposed by other researchers that there is an effect on synthesis product due to atomic hydrogen [56] and/or atomic nitrogen [63] produced by decomposition of ammonia. These contributing factors 


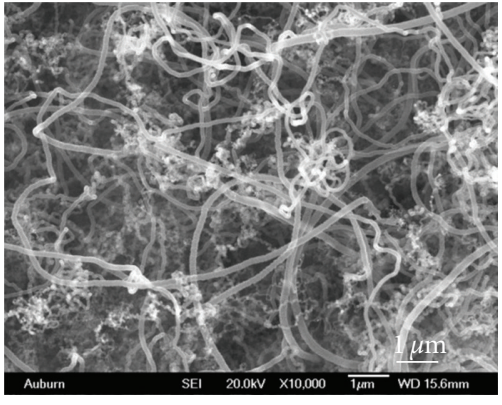

(a)

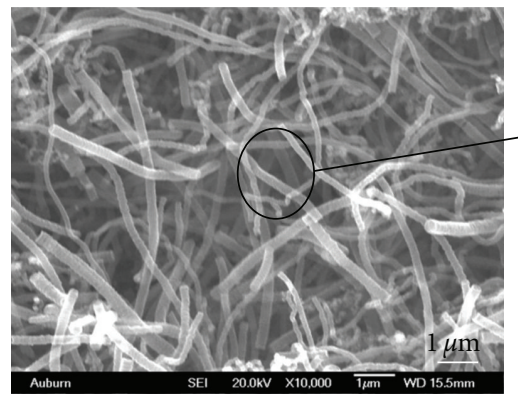

(b1)

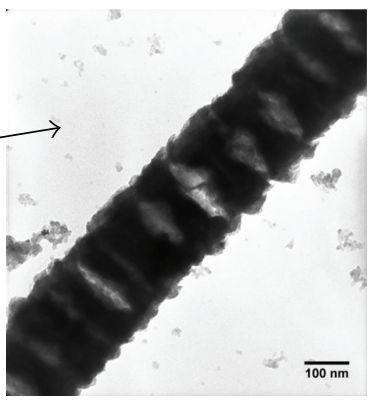

(b2)

FIGURE 10: Synthesized CNF for effect of $20 \% \mathrm{NH}_{3}$ on different pretreated foils: (a) SEM of CNF on $715^{\circ} \mathrm{C}$ reduction pretreatment, (b1) SEM of CNF on $815^{\circ} \mathrm{C}$ faceting pretreatment, and (b2) TEM of b1. Synthesis conditions: $2 \% \mathrm{C}_{2} \mathrm{H}_{2}, 20 \% \mathrm{NH}_{3}, 78 \% \mathrm{H}_{2}$, and $570^{\circ} \mathrm{C}(\mathrm{Table} 1$ (Phase 4C)).

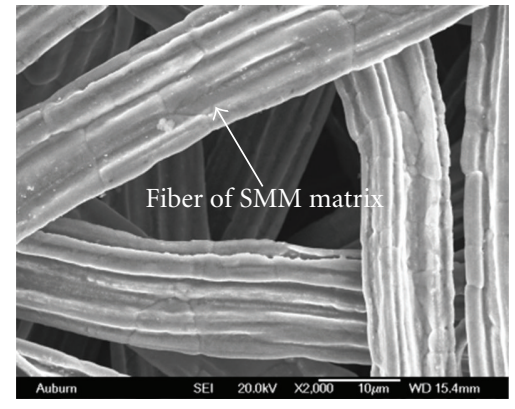

(a)

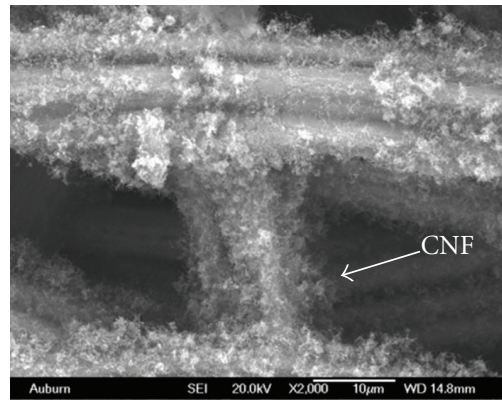

(b)

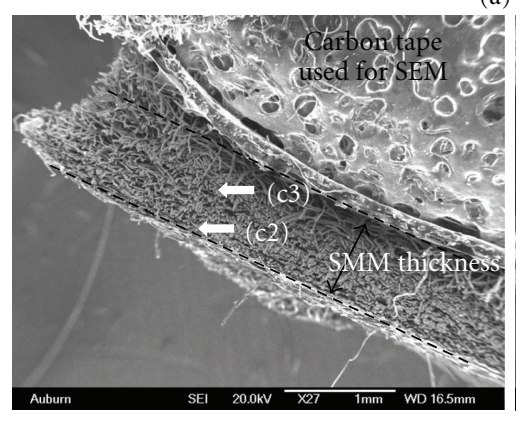

(c1)

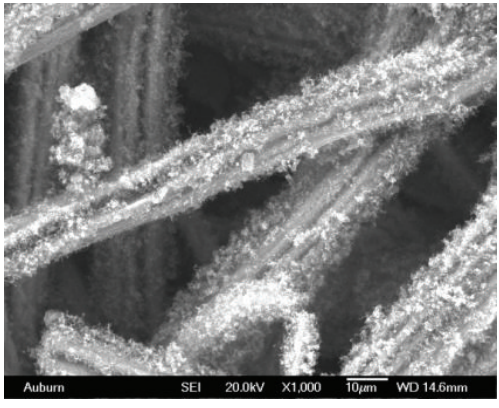

(c2)

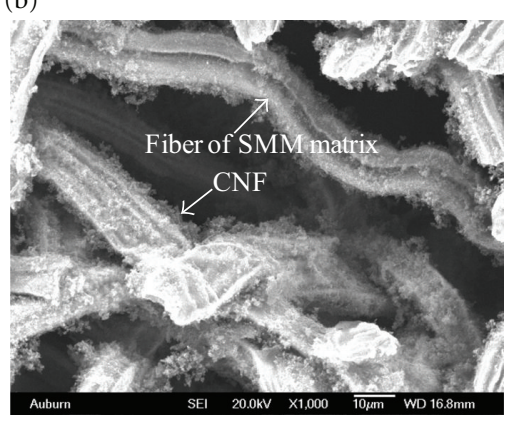

(c3)

Figure 11: 3-dimensional deposition of CNF within $8 \mu \mathrm{m}$ SMM matrix: (a) top-view before synthesis, (b) top-view after CNF 11 min synthesis, (c1) low magnification (27x) cross-sectional view, (c2) cross-sectional view at 1000x of the matrix edge shown in c1, and (c3) cross-sectional view at 1000x of the matrix thickness centerline shown in c1 [46].

may have modified the morphology of carbon deposits due to ammonia addition in the synthesis gas. However, the role of ammonia during CNF growth is not very well understood and requires further investigation.

\section{Conclusion}

Carbon nanofiber (CNF) synthesis on nickel sintered metal microfibrous (SMM) substrates was optimized for two different reaction conditions: (a) high rates of reaction for surface synthesis of CNF and (b) low rates of reaction for uniform 3-dimensional synthesis of CNF within SMM matrices. This optimization was done with the intended applications in aerosol filtration and membrane technology. Nickel foil was used as a tool to simplify the analyses by simulating the surface of microfibers within SMM matrices. Univariant optimization was used in this study. Factors considered during optimization were the rate of reaction and the quality of CNF produced. Redox faceting pretreatment, synthesis temperature, hydrogen concentration and ammonia concentration were the parameters optimized. During the optimization for high rates of reaction, it was found that redox faceting pretreatment introduced additional grain boundaries and increased the catalytic activity of the nickel substrate resulting in an 8-fold increase in the carbon yield. In the temperature range from $470^{\circ} \mathrm{C}$ to $670^{\circ} \mathrm{C}$, carbon yield 


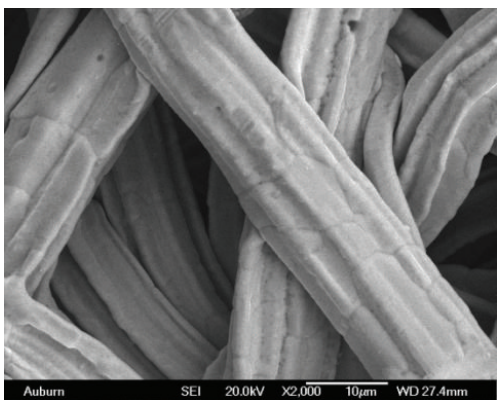

(a)

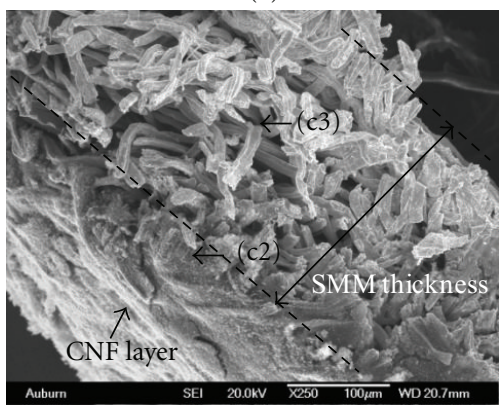

$(\mathrm{c} 1)$

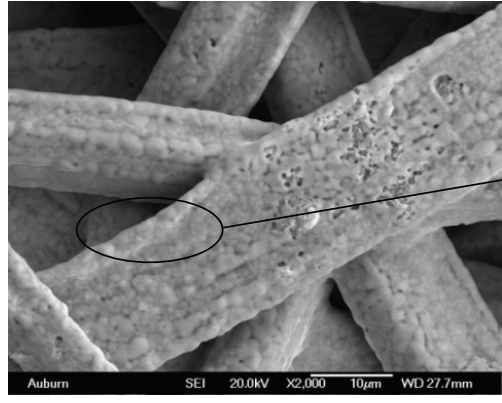

(b1)

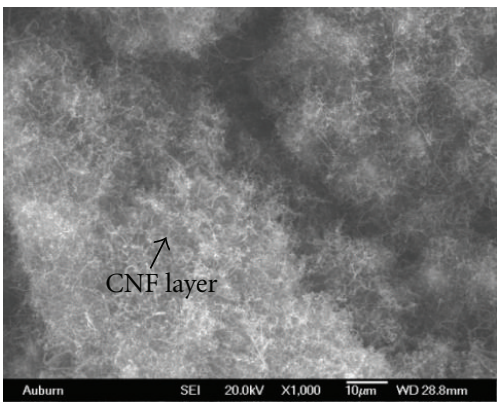

(c2)

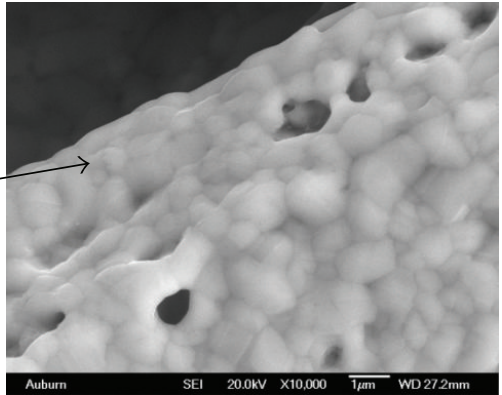

(b2)

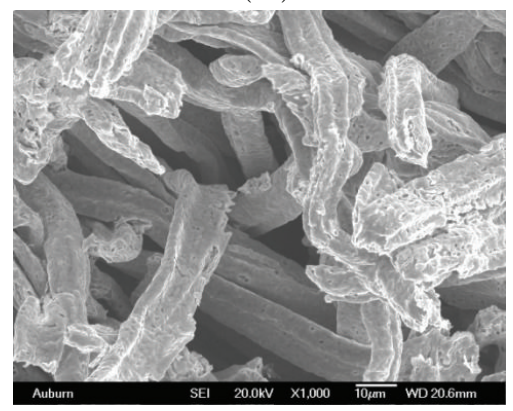

(c3)

FIGURE 12: Surface deposition of CNF on $8 \mu \mathrm{m}$ SMM matrix: (a) SMM matrix, (b1) faceted SMM matrix, (b2) high magnification (10000x) of faceted SMM matrix, (c1) cross-sectional view after 11 min synthesis $(250 \mathrm{x})$, (c2) cross-sectional view at 1000x of the surface shown in $\mathrm{c} 1$, and (c3) cross-sectional view at 1000x of the matrix thickness centerline shown in $\mathrm{c} 1$.

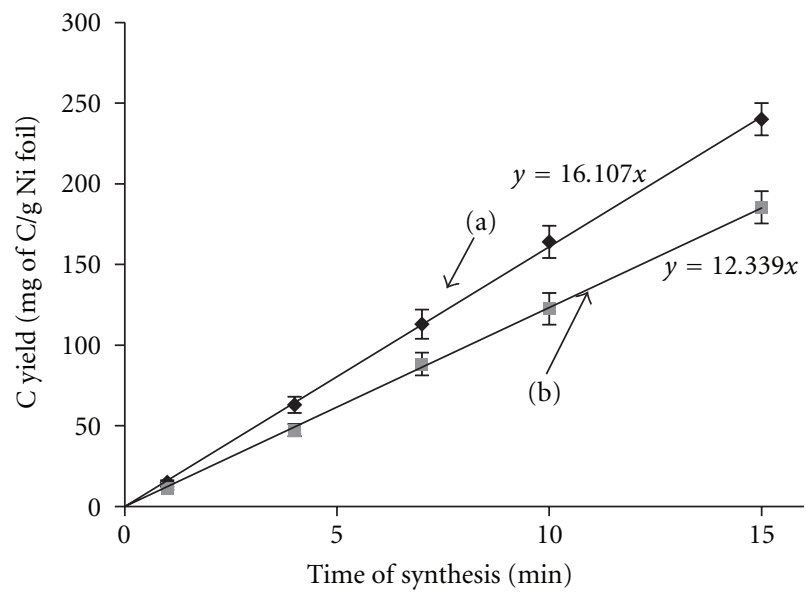

Figure 13: Yield of carbon versus time. (a) $815^{\circ} \mathrm{C}$ faceted foil; $2 \%$ $\mathrm{C}_{2} \mathrm{H}_{2}, 20 \% \mathrm{NH}_{3}, 78 \% \mathrm{H}_{2}$, and $570^{\circ} \mathrm{C}$. (b) $715^{\circ} \mathrm{C}$ reduced foil; $2 \%$ $\mathrm{C}_{2} \mathrm{H}_{2}, 98 \% \mathrm{H}_{2}$, and $570^{\circ} \mathrm{C}$.

increased with increase in the concentration of hydrogen. Ammonia (20\%) in the synthesis gas reduced the quantity of amorphous carbon.

For surface deposition of CNF on SMM matrices (which requires a high rate of reaction), the optimum synthesis conditions were $570^{\circ} \mathrm{C}, 78 \%$ hydrogen, $20 \%$ ammonia, and $2 \%$ acetylene on $815^{\circ} \mathrm{C}$ faceted nickel. For 3-dimensional deposition of CNF within SMM matrices (which requires a low rate of reaction), the optimum synthesis conditions were
$470{ }^{\circ} \mathrm{C}, 10 \%$ hydrogen, $88 \%$ nitrogen and $2 \%$ acetylene on nonfaceted nickel.

\section{Acknowledgment}

Financial support from US army TARDEC (Contract no. W56HZV-05-C-0686) is gratefully acknowledged.

\section{References}

[1] T. Baird, J. R. Fryer, and B. Grant, "Carbon formation on iron and nickel foils by hydrocarbon pyrolysis-reactions at $700^{\circ} \mathrm{C}$," Carbon, vol. 12, no. 5, pp. 591-602, 1974.

[2] J. L. Figueredo and D. L. Trimm, "Carbon formation on unsupported and supported nickel catalysts," Journal of Applied Chemistry \& Biotechnology, vol. 28, no. 9, pp. 611-616, 1978.

[3] L. S. Lobo and D. L. Trimm, "Carbon formation from light hydrocarbons on nickel," Journal of Catalysis, vol. 29, no. 1, pp. 15-19, 1973.

[4] L. S. Lobo and D. L. Trimm, "Studies of carbon formation on metals using a vacuum microobalance," Progress in Vacuum Microbalance Techniques, vol. 2, pp. 1-8, 1973.

[5] P. A. Tesner, E. Y. Robinovich, I. S. Rafalkes, and E. F. Arefieva, "Formation of carbon fibers from acetylene," Carbon, vol. 8, no. 4, pp. 433-442, 1970.

[6] Y. Nishiyama and Y. Tamai, "Carbon formation on coppernickel alloys from benzene," Journal of Catalysis, vol. 33, no. 1, pp. 98-107, 1974.

[7] A. Oberlin, M. Endo, and T. Koyama, "Filamentous growth of carbon through benzene decomposition," Journal of Crystal Growth, vol. 32, no. 3, pp. 335-349, 1976. 
[8] H. W. Kroto, J. R. Heath, S. C. O'Brien, R. F. Curl, and R. E. Smalley, "C60: buckminsterfullerene," Nature, vol. 318, no. 6042, pp. 162-163, 1985.

[9] S. Iijima, "Helical microtubules of graphitic carbon," Nature, vol. 354 , no. 6348 , pp. 56-58, 1991.

[10] L. A. Chernozatonskii, E. F. Kukovitskii, A. L. Musatov, A. B. Ormont, K. R. Izraeliants, and S. G. L'vov, "Carbon crooked nanotube layers of polyethylene: synthesis, structure and electron emission," Carbon, vol. 36, no. 5-6, pp. 713-715, 1998.

[11] A. L. Musatov, N. A. Kiselev, D. N. Zakharov et al., "Field electron emission from nanotube carbon layers grown by CVD process," Applied Surface Science, vol. 183, no. 1-2, pp. 111$119,2001$.

[12] Y. Saito, K. Hata, A. Takakura, J. Yotani, and S. Uemura, "Field emission of carbon nanotubes and its application as electron sources of ultra-high luminance light-source devices," Physica $B$, vol. 323, no. 1-4, pp. 30-37, 2002.

[13] P. Avouris, R. Martel, V. Derycke, and J. Appenzeller, "Carbon nanotube transistors and logic circuits," Physica B, vol. 323, no. 1-4, pp. 6-14, 2002.

[14] P. G. Collins, M. S. Arnold, and P. Avouris, "Engineering carbon nanotubes and nanotube circuits using electrical breakdown," Science, vol. 292, no. 5517, pp. 706-709, 2001.

[15] A. Bachtold, P. Hadley, T. Nakanishi, and C. Dekker, "Logic circuits with carbon nanotube transistors," Science, vol. 294, no. 5545, pp. 1317-1320, 2001.

[16] V. Derycke, R. Martel, J. Appenzeller, and P. Avouris, "Carbon nanotube inter- and intramolecular logic gates," Nano Letters, vol. 1, no. 9, pp. 453-456, 2001.

[17] C. Zhou, J. Kong, E. Yenilmez, and H. Dai, "Modulated chemical doping of individual carbon nanotubes," Science, vol. 290, no. 5496, pp. 1552-1555, 2000.

[18] P. Sharma and P. Ahuja, "Recent advances in carbon nanotube-based electronics," Materials Research Bulletin, vol. 43, no. 10, pp. 2517-2526, 2008.

[19] A. P. Graham, G. S. Duesberg, W. Hoenlein et al., "How do carbon nanotubes fit into the semiconductor roadmap?" Applied Physics A, vol. 80, no. 6, pp. 1141-1151, 2005.

[20] A. R. Bhattacharyya, T. V. Sreekumar, T. Liu et al., "Crystallization and orientation studies in polypropylene/single wall carbon nanotube composite," Polymer, vol. 44, no. 8, pp. 2373-2377, 2003.

[21] M. J. Biercuk, M. C. Llaguno, M. Radosavljevic, J. K. Hyun, A. T. Johnson, and J. E. Fischer, "Carbon nanotube composites for thermal management," Applied Physics Letters, vol. 80, no. 15, pp. 2767-2769, 2002.

[22] M. Cadek, J. N. Coleman, V. Barron, K. Hedicke, and W. J. Blau, "Morphological and mechanical properties of carbonnanotube-reinforced semicrystalline and amorphous polymer composites," Applied Physics Letters, vol. 81, no. 27, pp. 5123$5125,2002$.

[23] Y. T. Jang, J. H. Ahn, Y. H. Lee, and B. K. Ju, "Effect of $\mathrm{NH}_{3}$ and thickness of catalyst on growth of carbon nanotubes using thermal chemical vapor deposition," Chemical Physics Letters, vol. 372, no. 5-6, pp. 745-749, 2003.

[24] W. Z. Li, D. Z. Wang, S. X. Yang, J. G. Wen, and Z. F. Ren, "Controlled growth of carbon nanotubes on graphite foil by chemical vapor deposition," Chemical Physics Letters, vol. 335, no. 3-4, pp. 141-149, 2001.

[25] N. J. Jeong, J. H. Lee, Y. H. Kim, J. H. Kim, and H. Y. Kim, "High-density growth of carbon nanotubes with catalytic sites activated on nickel substrate," Research on Chemical Intermediates, vol. 34, no. 8-9, pp. 761-766, 2008.
[26] P. Nikolaev, M. J. Bronikowski, R. K. Bradley et al., "Gasphase catalytic growth of single-walled carbon nanotubes from carbon monoxide," Chemical Physics Letters, vol. 313, no. 1-2, pp. 91-97, 1999.

[27] M. J. Bronikowski, P. A. Willis, D. T. Colbert, K. A. Smith, and R. E. Smalley, "Gas-phase production of carbon single-walled nanotubes from carbon monoxide via the HiPco process: a parametric study," Journal of Vacuum Science \& Technology A, vol. 19, no. 4, part 1, pp. 1800-1805, 2001.

[28] B. C. Satishkumar, A. Govindaraj, R. Sen, and C. N. R. Rao, "Single-walled nanotubes by the pyrolysis of acetyleneorganometallic mixtures," Chemical Physics Letters, vol. 293, no. 1-2, pp. 47-52, 1998.

[29] R. Sen, A. Govindaraj, and C. N. R. Rao, "Carbon nanotubes by the metallocene route," Chemical Physics Letters, vol. 267, no. 3-4, pp. 276-280, 1997.

[30] R. L. Vander Wal and L. J. Hall, "Carbon nanotube synthesis upon stainless steel meshes," Carbon, vol. 41, no. 4, pp. 659672, 2003.

[31] S. J. Park and D. G. Lee, "Performance improvement of micron-sized fibrous metal filters by direct growth of carbon nanotubes," Carbon, vol. 44, no. 10, pp. 1930-1935, 2006.

[32] S. J. Park and D. G. Lee, "Development of CNT-metal-filters by direct growth of carbon nanotubes," Current Applied Physics, vol. 6, no. 1, pp. e182-e186, 2006.

[33] D. Park, Y. H. Kim, and J. K. Lee, "Synthesis of carbon nanotubes on metallic substrates by a sequential combination of PECVD and thermal CVD," Carbon, vol. 41, no. 5, pp. 10251029, 2003.

[34] M. Karwa, Z. Iqbal, and S. Mitra, "Scaled-up self-assembly of carbon nanotubes inside long stainless steel tubing," Carbon, vol. 44, no. 7, pp. 1235-1242, 2006.

[35] Y. Soneda and M. Makino, "Formation and texture of carbon nanofilaments by the catalytic decomposition of $\mathrm{CO}$ on stainless-steel plate," Carbon, vol. 38, no. 3, pp. 478-480, 2000.

[36] N. Jeong and J. Lee, "Growth of filamentous carbon by decomposition of ethanol on nickel foam: influence of synthesis conditions and catalytic nanoparticles on growth yield and mechanism," Journal of Catalysis, vol. 260, no. 2, pp. 217-226, 2008.

[37] W. Huang, X. B. Zhang, J. Tu et al., "Synthesis and characterization of graphite nanofibers deposited on nickel foams," Physical Chemistry Chemical Physics, vol. 4, no. 21, pp. 53255329, 2002.

[38] N. A. Jarrah, F. Li, J. G. Van Ommen, and L. Lefferts, "Immobilization of a layer of carbon nanofibres (CNFs) on Ni foam: a new structured catalyst support," Journal of Materials Chemistry, vol. 15, no. 19, pp. 1946-1953, 2005.

[39] C. Du and N. Pan, "CVD growth of carbon nanotubes directly on nickel substrate,” Materials Letters, vol. 59, no. 13, pp. 1678-1682, 2005.

[40] A. Sacco Jr., F. W. A. H. Geurts, G. A. Jablonski, S. Lee, and R. A. Gately, "Carbon deposition and filament growth on Fe, Co, and $\mathrm{Ni}$ foils using $\mathrm{CH}_{4} \mathrm{H}_{2} \mathrm{H}_{2} \mathrm{OCOCO}_{2}$ gas mixtures," Journal of Catalysis, vol. 119, no. 2, pp. 322-341, 1989.

[41] P. S. Guo, Z. Sun, Y. W. Chen, and Z. H. Zheng, "A novel approach to mass synthesis of raw CNTs for printed field emission cathodes by chemical vapour deposition," Materials Letters, vol. 60, no. 7, pp. 966-969, 2006.

[42] E. F. Kukovitsky, S. G. L'vov, N. A. Sainov, and V. A. Shustov, "CVD growth of carbon nanotube films on nickel substrates," Applied Surface Science, vol. 215, no. 1-4, pp. 201-208, 2003. 
[43] W. Wunderlich, "Growth model for plasma-CVD growth of carbon nano-tubes on Ni-sheets," Diamond and Related Materials, vol. 16, no. 2, pp. 369-378, 2007.

[44] C. Masarapu, V. Subramanian, H. Zhu, and B. Wei, "Longcycle electrochemical behavior of multiwall carbon nanotubes synthesized on stainless steel in Li ion batteries," Advanced Functional Materials, vol. 19, no. 7, pp. 1008-1014, 2009.

[45] V. Martínez-Hansen, N. Latorre, C. Royo, E. Romeo, E. García-Bordejé, and A. Monzón, "Development of aligned carbon nanotubes layers over stainless steel mesh monoliths," Catalysis Today, vol. 147, supplement, pp. S71-S75, 2009.

[46] A. N. Karwa and B. J. Tatarchuk, "Aerosol filtration enhancement using carbon nanostructures synthesized within a sintered nickel microfibrous matrix," Separation and Purification Technology, vol. 87, pp. 84-94, 2012.

[47] C. Bernardo and D. L. Trimm, "Structural factors in the deposition of carbon on nickel," Carbon, vol. 14, no. 4, pp. 225-228, 1976.

[48] N. K. Reddy, J. L. Meunier, and S. Coulombe, "Growth of carbon nanotubes directly on a nickel surface by thermal CVD," Materials Letters, vol. 60, no. 29-30, pp. 3761-3765, 2006.

[49] L. E. Cratty Jr. and A. V. Granato, "Dislocations as "Active Sites" in heterogeneous catalysis," The Journal of Chemical Physics, vol. 26, no. 1, pp. 96-97, 1957.

[50] C. A. Bernardo and L. S. Lobo, "Kinetics of carbon formation from acetylene on nickel," Journal of Catalysis, vol. 37, no. 2, pp. 267-278, 1975.

[51] R. T. K. Baker and J. J. Chludzinski Jr., "Filamentous carbon growth on nickel-iron surfaces: the effect of various oxide additives," Journal of Catalysis, vol. 64, no. 2, pp. 464-478, 1980.

[52] R. T. K. Baker, M. A. Barber, P. S. Harris, F. S. Feates, and R. J. Waite, "Nucleation and growth of carbon deposits from the nickel catalyzed decomposition of acetylene," Journal of Catalysis, vol. 26, no. 1, pp. 51-62, 1972.

[53] Y. Nishiyama and Y. Tamai, "Effect of hydrogen on carbon deposition catalyzed by copper-nickel alloys," Journal of Catalysis, vol. 45, no. 1, pp. 1-5, 1976.

[54] M. S. Kim, N. M. Rodriguez, and R. T. K. Baker, "The interaction of hydrocarbons with coppernickel and nickel in the formation of carbon filaments," Journal of Catalysis, vol. 131, no. 1, pp. 60-73, 1991.

[55] R. T. K. Baker, P. S. Harris, R. B. Thomas, and R. J. Waite, "Formation of filamentous carbon from iron, cobalt and chromium catalyzed decomposition of acetylene," Journal of Catalysis, vol. 30, no. 1, pp. 86-95, 1973.

[56] G. S. Choi, Y. S. Cho, S. Y. Hong, J. B. Park, K. H. Son, and D. J. Kim, "Carbon nanotubes synthesized by Ni-assisted atmospheric pressure thermal chemical vapor deposition," Journal of Applied Physics, vol. 91, no. 6, pp. 3847-3854, 2002.

[57] C. J. Lee, J. Park, Y. Huh, and J. Yong Lee, “Temperature effect on the growth of carbon nanotubes using thermal chemical vapor deposition," Chemical Physics Letters, vol. 343, no. 1-2, pp. 33-38, 2001.

[58] C. J. Lee, J. Park, S. Y. Kang, and J. H. Lee, "Growth of well-aligned carbon nanotubes on a large area of $\mathrm{Co}-\mathrm{Ni}$ codeposited silicon oxide substrate by thermal chemical vapor deposition," Chemical Physics Letters, vol. 323, no. 5-6, pp. 554-559, 2000.

[59] Z. P. Huang, D. Z. Wang, J. G. Wen, M. Sennett, H. Gibson, and Z. F. Ren, "Effect of nickel, iron and cobalt on growth of aligned carbon nanotubes," Applied Physics A, vol. 74, no. 3, pp. 387-391, 2002.

[60] Z. P. Huang, J. W. Xu, Z. F. Ren, J. H. Wang, M. P. Siegal, and P. N. Provencio, "Growth of highly oriented carbon nanotubes by plasma-enhanced hot filament chemical vapor deposition," Applied Physics Letters, vol. 73, no. 26, pp. 3845-3847, 1998.

[61] Z. Y. Juang, I. P. Chien, J. F. Lai, T. S. Lai, and C. H. Tsai, "The effects of ammonia on the growth of large-scale patterned aligned carbon nanotubes using thermal chemical vapor deposition method," Diamond and Related Materials, vol. 13, no. 4-8, pp. 1203-1209, 2004.

[62] S. Wei, W. P. Kang, J. L. Davidson, and J. H. Huang, "Aligned carbon nanotubes fabricated by thermal CVD at atmospheric pressure using Co as catalyst with $\mathrm{NH}_{3}$ as reactive gas," Diamond and Related Materials, vol. 15, no. 11-12, pp. 18281833, 2006.

[63] M. Jung, K. Y. Eun, Y. J. Baik, K. R. Lee, J. K. Shin, and S. T. Kim, "Effect of $\mathrm{NH}_{3}$ environmental gas on the growth of aligned carbon nanotube in catalystically pyrolizing $\mathrm{C}_{2} \mathrm{H}_{2}$," Thin Solid Films, vol. 398-399, pp. 150-155, 2001.

[64] Z. F. Ren, Z. P. Huang, J. W. Xu et al., "Synthesis of large arrays of well-aligned carbon nanotubes on glass," Science, vol. 282, no. 5391, pp. 1105-1107, 1998.

[65] Y. Chen, S. Patel, Y. Ye, D. T. Shaw, and L. Guo, "Field emission from aligned high-density graphitic nanofibers," Applied Physics Letters, vol. 73, no. 15, pp. 2119-2121, 1998.

[66] C. Bower, W. Zhu, S. Jin, and O. Zhou, "Plasma-induced alignment of carbon nanotubes," Applied Physics Letters, vol. 77, no. 6, pp. 830-832, 2000.

[67] S. F. Lee, Y. P. Chang, and L. Y. Lee, "Effects of annealing Ni catalyst in nitrogen-containing gases on the surface morphology and field-emission properties of thermal chemical vapor deposited carbon nanotubes," Xinxing Tan Cailiao, vol. 23, no. 4, pp. 302-308, 2008.

[68] C. F. Cullis and N. H. Franklin, "The pyrolysis of acetylene at temperatures from 500 to 1000 Deg," Proceedings of the Royal Society A, vol. 280, no. 1380, pp. 139-152, 1964.

[69] A. E. B. Presland and P. L. Walker, "Growth of single-crystal graphite by pyrolysis of acetylene over metals," Carbon, vol. 7, no. 1, pp. 1-8, 1969.

[70] M. S. Kim, N. M. Rodriguez, and R. T. K. Baker, "The interplay between sulfur adsorption and carbon deposition on cobalt catalysts," Journal of Catalysis, vol. 143, no. 2, pp. 449-463, 1993.

[71] R. W. McCabe, "Kinetics of ammonia decomposition on nickel," Journal of Catalysis, vol. 79, no. 2, pp. 445-450, 1983.

[72] A. E. Shalagina, Z. R. Ismagilov, O. Y. Podyacheva, R. I. Kvon, and V. A. Ushakov, "Synthesis of nitrogen-containing carbon nanofibers by catalytic decomposition of ethylene/ammonia mixture," Carbon, vol. 45, no. 9, pp. 1808-1820, 2007. 

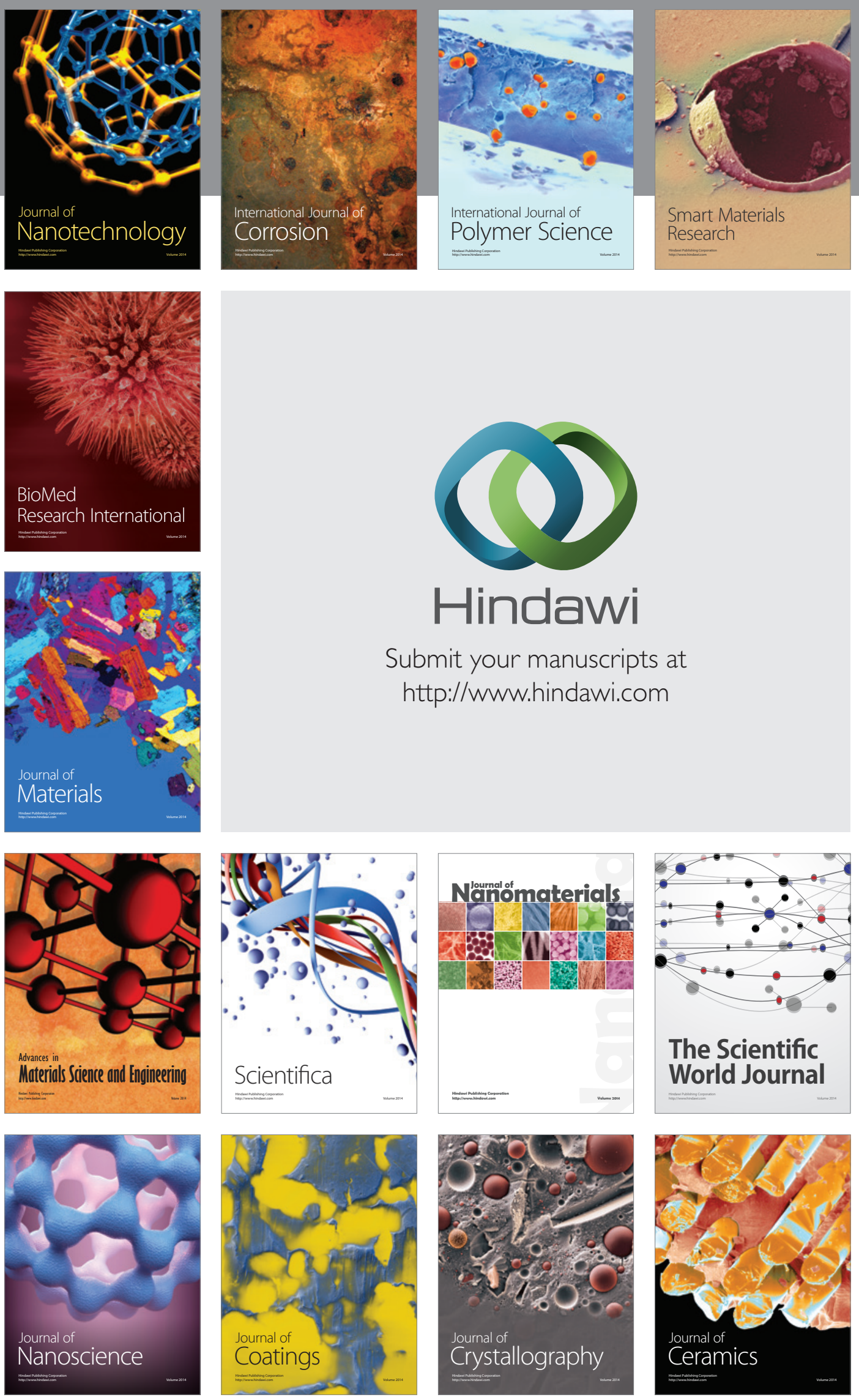

The Scientific World Journal

Submit your manuscripts at

http://www.hindawi.com

\section{World Journal}

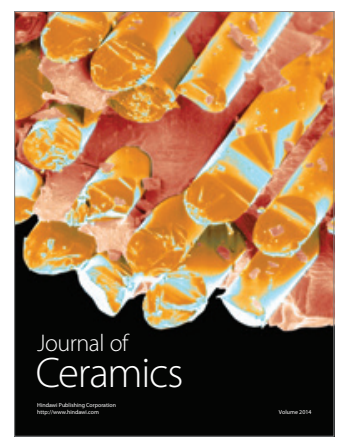

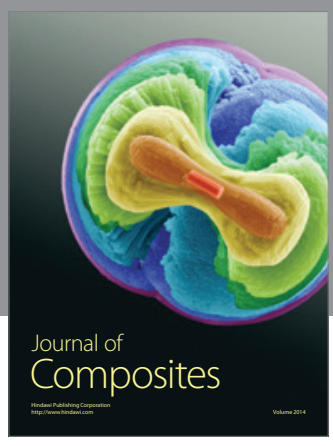
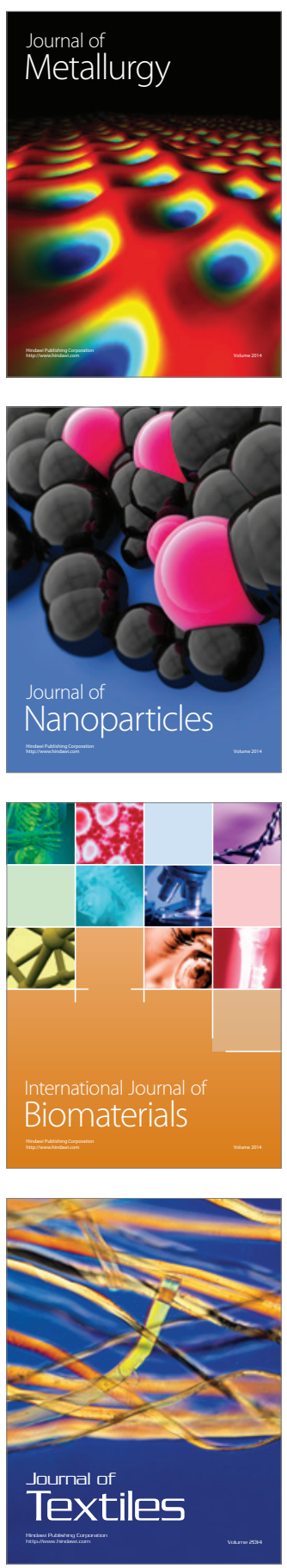